\title{
LA RELACIÓN SOCIAL COMO CATEGORÍA DE LAS CIENCIAS SOCIALES ${ }^{1}$
}

\section{Manuel Herrera Gómez}

Universidad de Granada

E-mail: mherrera@goliat.ugr.es

\begin{abstract}
RESUMEN
En estas páginas se pretende ofrecer la clave de lectura de la sociedad como relación. Se intenta aclarar en qué sentido la relación social es objeto de conocimiento sociológico, cómo puede ser observada y cómo la sociedad es un continuo proceso de asociación y disociación, es decir, de diferenciación que no siempre es lineal y continua, sino, también, no-lineal (asimétrica) e involutiva (no evolucionista en sentido darwiniano, como tradicionalmente se ha pensado).
\end{abstract}

\section{LA RELACIÓN SOCIAL COMO OBJETO DE CONOCIMIENTO}

En cierto sentido, en el campo de las Ciencias Sociales, la relación social (su estructura, contenido, articulación y cambio) tiene la misma importancia que la célula en biología: la relación social es la célula del tejido social (conviene puntualizar que en ningún momento esto significa una reificación del concepto y de la realidad significada). Respecto a otros órdenes de realidad, la relacionalidad es lo que caracteriza (en sentido fuerte) el género específico de lo social.

1 Agradezco a los profesores Julio Iglesias de Ussel, Andrés Ollero, Pedro Castón, Antonio Trinidad (Universidad de Granada), José Juan Toharia (Universidad Autónoma de Madrid) y Pierpaolo Donati (Universidad de Bolonia) las orientaciones y sugerencias que me hicieron en la elaboración de este trabajo. 
Por relación social debe entenderse la realidad inmaterial (que está en el espacio-tiempo) de lo interhumano, es decir, aquello que está entre los sujetos agentes. Como tal, constituye su orientarse y obrar recíproco, distinguiéndose de lo que está en los singulares actores —individuales o colectivos- considerados como polos o términos de la relación. Esta «realidad entre», hecha conjuntamente de elementos «objetivos» (independientes de los sujetos: propiedades del sistema de interacción como tal) y «subjetivos» (dependientes de la subjetividad: condiciones y características de la comunicación intersubjetiva), es la esfera en que se definen tanto la distancia como la integración de los individuos respecto a la sociedad: de ella depende si, en qué forma, medida y cualidad el individuo puede distanciarse o implicarse respecto a otros sujetos, a las instituciones y, en general, respecto a las dinámicas de la vida social (P. Donati, 1986).

Este punto de vista no ha emergido de forma inmediata. Para observar esta "realidad entre», con sus componentes, articulaciones y vicisitudes, han sido necesarias muchas distinciones y desarrollos de pensamiento que se han ido produciendo de forma gradual a lo largo de la historia. Aún más, siempre está abierta la cuestión entre las características (libres, racionales, deliberativas, significativas) propias y solamente humanas de la relación social, y las características (genéticas, instintivas, mecánicas, automáticas) de las relaciones sociales ("naturales») existentes entre los seres vivientes no humanos. En cualquier caso, toda relación social ya no aparece como inmediatamente humana, sino como una intersección de elementos en parte propiamente humanos $\mathrm{y}$, en parte, no específicos de lo humano (T. Benton, 1993).

En el pensamiento de la Grecia clásica, al no existir un concepto específico de lo "social» (éste es absorbido en el concepto de lo "político»), es impropio hablar de relación social. En Aristóteles, la categoría filosófica de relación (pros ti —Cat., 7, 6a-, locución adverbial cuyo significado es: "en relación a» lo que tiene realidad sustancial) es una noción primera que no admite definición. Primariamente indica una referencia de razón. En líneas generales, cuando se convierte en objeto de observación empírica, en la filosofía aristotélica la relación social como tal asume un carácter de realidad derivada y naturalista. Se supone que procede de la misma naturaleza de los seres vivientes.

Tampoco la cultura romana posee un concepto específico de relación social. Aunque conviene recordar que en ella se nos ofrece la raíz etimológica de relatio. Ésta indica la referencia de un ente o de un objeto a otro según un determinado modo que puede ser propio de las cosas mismas entre sí o bien puesto por la mente entre las cosas. Del resto, tampoco el Derecho Romano conoce el concepto de relación jurídica, que, "entendida como relación de persona a persona, determinada por una regla jurídica», aparece con la pandectística.

Entre los siglos XII y XIII, en el marco del complejo cambio social que marca el comienzo de la época moderna, se inicia el desarrollo de una «doctrina de las relaciones» (Tomás de Aquino, Duns Scoto y otros) (A. Krempel, 1952; I. Miralbell, 1994). El interés por el concepto de relación es prioritariamente 
metafísico, pero asistimos a un lento caminar en sentido gnoseológico que precede a los desarrollos lógico-formales que serán propios de la modernidad (R. P. Horstmann, 1984). Cuando el concepto de relación venga aplicado a la esfera del pensamiento social y político nos encontraremos ante los primeros pasos de la investigación sobre la relación como constitutivo de lo social. Las primeras expresiones aparecerán en el empirismo inglés y en el idealismo alemán de los siglos XVIII y XIX, es decir, en las dos tradiciones (anglosajona y europeo-continental) que caracterizan la idea moderna de sociedad civil.

En el específico campo de las Ciencias Sociales, una concreta "doctrina de las relaciones sociales» aflorará en los últimos años del siglo XIX y en los primeros decenios del XX. Las aportaciones fundamentales proceden de las escuelas británica (los seguidores de J. Locke y D. Hume, de los moralistas escoceses y de H. Spencer), francesa (G. Tarde y E. Durkheim) y americana (en concreto, E. A. Ross y la escuela de Chicago, además de las diversas corrientes del pragmatismo, desde C. S. Peirce a G. H. Mead). Pero es concretamente en Alemania (con G. Simmel, M. Weber, L. von Wiese y, posteriormente, con la fenomenología de E. Husserl) donde se experimenta el "cambio relacional» en las Ciencias Sociales.

Como dijo J. Gottman, el desafío ante el que nos encontramos "consiste en la búsqueda de un lenguaje científico para describir las relaciones" (1982: 943). Cambio relacional significa el tránsito desde un "pensamiento entitativo" (no relacional) que razona y observa "por entidades», queriendo conocer aquello que existe en sí y por sí (a partir de categorías), a un "pensamiento relacional» que opera distinguiendo reflexivamente "por relaciones», orientándose de cualquier manera a la construcción del propio objeto (lo que existe-en-relación). Es decir, pasamos de un modo de organizar mapas cognitivos y simbólicos que atribuyen las cualidades a los entes a partir de su naturaleza, sin contemplar el contexto relacional en el que dichos entes se sitúan y existen, a un modo de pensar que organiza los propios mapas cognitivos y simbólicos atribuyendo las cualidades a los entes, pero no a partir de una supuesta identidad, sino definiendo tal identidad como realidad relacional de un ente-en-un-contexto. Dicho contexto puede ser conceptualizado de diversas formas y, normalmente, debe tener en cuenta tanto al observador como a lo observado (P. Donati, 1991). Por tanto, debe dialogar con meta-puntos-de-vista. Que pueda ser indicado y descrito como «sistema» es una posibilidad entre otras.

La perspectiva que presenta a la relación como la categoría fundamental del pensamiento social (A. Vierkandt, 1915), unido a la idea de que nuestra realidad se amplía tanto como nuestras relaciones (J. Plenge, 1930), indica la apertura de nuevos horizontes para las Ciencias Sociales, horizontes que ya no podrán cerrarse. Especialmente si consideramos la explosión de la realidad (sociedad) virtual. De manera emblemática, la perspectiva relacional no sólo revela el inicio de una nueva época del pensamiento social; también, de ahora en adelante, es la teoría de las relaciones la que decide la capacidad de comprensión, explicación y acción de cualquier teoría particular. 
En líneas generales, se debe observar que, desde los inicios de la época moderna, y dentro de la modernidad, la relación social es concebida como entidad implícita (más que explícita) y derivada (más que autónoma), y, a menudo, sólo como mediación respecto a otras entidades o variables subjetivas -individuales o colectivas - y estructurales. Es decir, muy raramente nos encontramos con una reflexión que trate la relación social como objeto de conocimiento en sí mismo. Hasta el día de hoy, dos han sido las modalidades de tratar la relación social:

a) La relación como proyección, reflejo o producto de los singulares individuos, $y$ de sus acciones. Dicho de otro modo, la relación es reconducida a orientaciones de valores y normativas del individuo (no en cuanto personalidad en sí misma, que es más bien objeto de la psicología, sino en cuanto agente social), de un individuo inmerso en una cierta cultura o subcultura (pensemos, por ejemplo, en las investigaciones de M. Weber sobre la ética protestante como factor que incentiva el capitalismo).

b) La relación como expresión y efecto de estructuras sociales, de estatus-rol, de una totalidad o de un sistema social global. En este caso, la relación es reconducida a datos estructurales, a la situación y a las instituciones, es decir, a las redes de los estatus-roles y de las relaciones objetivas en que vienen organizados los procesos sociales y a través de los que las posiciones de los individuos, de los grupos y de los subgrupos vienen diferenciadas (por ejemplo, ciertos aspectos de los análisis de Marx sobre las estructuras de clase, o bien el estudio de Simmel sobre coaliciones en las triadas).

El debate epistemológico actual oscila entre dos grandes corrientes:

1) El individualismo metodológico, basado en el conocimiento social "comprensivo" (que no significa ipso facto empático o intuitivo) de los agentes individuales. Trata de dar cuenta del mundo social adoptando una perspectiva interna de investigación que concibe la realidad como realidad simbólicamente estructurada, es decir, como "mundo vital» intrínsecamente significativo en cuanto que intersubjetivo.

2) El holismo metodológico, que se presenta como análisis de relaciones estructuradas e institucionalizadas del mundo social y, en consecuencia, adopta una postura externa. A través de ella intenta explicar los nexos y las regularidades no intuitivas de los procesos de acciones productivos de orden sistémico, prescindiendo de las subjetividades participantes ${ }^{2}$.

2 El intento más notable de "combinar» ambas corrientes ha sido el estructural-funcionalismo (T. Parsons, 1961, 1966), revisado por muchos (entre ellos, J. C. Alexander, 1983; R. Münch, 1989). Sin embargo, como bien ha señalado P. Donati (1993: 32-34), a pesar de tales tentativas, ha permanecido una evidente incomunicabilidad entre individualismo y holismo metodológico. 
Ambas corrientes poseen un mismo denominador común: atribuyen a la relación un rol derivado (antes que el ser una presuposición primera). Sin embargo, una ciencia relacional se desarrolla en la medida en que se asume que "al principio (sobreentiendo: de la acción, del fenómeno, del hecho social, de la experiencia) es la relación» $\mathrm{y}$, a partir de tal presuposición, se elabora una consiguiente metodología ${ }^{3}$. ¿Qué significa esto?

Diferenciando el discurso lógico del social, para Pierpaolo Donati (1991: 25-27) los significados e implicaciones de la anterior afirmación pueden quedar sintetizados así:

1) Ante todo, significa que la relación es una noción primera, no definible, sino sólo semantizable. Toda definición no puede ser más que tautológica: dice que un elemento es/estálexiste en/por relación a otro. Sin embargo, en la base de tal concepto hay un significado-guía: relatio es el nombre de la acción en el sistema del referre, es decir, del referir una cosa a otra; de aquí el significado de uso común de "relación» como reportage. En el plano lógico, la relación es el acto (mental) para distinguir una cosa (elemento o, incluso, relación) remitiéndola a otra cosa (elemento o relación).

2) En el plano de la teoría consiguiente, la relación es el medium de la relación misma; es la relación quien da vida al lenguaje y a la experiencia, que son —como otros muchos_ «bienes relacionales». El juego — pienso en H. G. Gadamer (1980), que lo teoriza como "filón ontológico»— no es más que uno de los posibles modos de ser de la relacionalidad. Aún más, la relación es un bien en sí, tiene valor.

3) La relación puede ser diferenciada en diversas formas según el punto de vista (sistema observante) y las distinciones que vienen utilizadas. La relación puede ser un acto meramente lógico-conceptual de la mente, puede ser una operación de la conciencia moral o bien del sistema de la personalidad, del sistema social o cultural.

4) Las ventajas que se derivan de la elección conceptual que sitúa a la relación como pre-supuesto constitutivo del mundo social son muchas: a diferencia del concepto de sistema o estructura, el concepto de relación es más rico ya que está construido contemporáneamente de manera compleja y paradójica sobre la trinidad de un referente y, al menos, dos relata; relación es unitas multiplex, todo y parte, diferenciación e integración; contiene elementos; siempre se deja relacionar posteriormente; se ubica en la línea de una red de relaciones; puede relacionar acontecimientos; permite el regreso (o, viceversa, el progreso) al

A pesar de constituir una interesante y elaborada respuesta al dilema entre individualismo y holismo metodológicos, así como todo un tratado de las diversas relaciones sociales, la obra de J. Coleman Foundations of Social Theory (1990) no representa un análisis de las relaciones sociales en sentido estricto. Personalmente, creo que dicho análisis implica un tercer punto de vista (ni individualista ni sistémico), que no está presente en el pensamiento de Coleman, que defina el propio objeto como relación y se centre en la relación como realidad y modalidad de investigación. 
infinito; consiente la elaboración de conceptos límite mediante el constante relacionamiento; es interrupción en relación a la relación última o al último elemento; es circularidad como relacionamiento de la última relación mediante la penúltima o como oscilación entre elementos y relaciones; por tanto: la autorreferencia sólo es un caso particular de relación, y lo mismo debe decirse de la heterorreferencia; tanto las acciones como los sistemas se dejan captar como relaciones.

5) El concepto de relación es relevante tanto como estructura como acontecimiento, pero ambos se colocan en niveles diferentes: como estructura se refiere al nivel supuesto de la teoría y de los patterns contextuales, como acontecimiento alude al nivel empírico de los hechos y de sus actualizaciones.

6) Las relaciones sociales pueden ser diferenciadas según el nivel desde el que son observadas: como interacciones, organizaciones y sociedad. A menudo, cuando se habla de relaciones como sucesos, se alude a las relaciones entendidas como interacciones; pero, en cualquier caso, estructura y suceso siempre están copresentes.

7) La relación social se diferencia del suceso, por lo menos, en dos aspectos: primero, tiene duración (por tanto, historia), mientras que el suceso no tiene duración (no tiene historia); segundo, está determinada (está vinculada), mientras que el suceso es casual; ya que el suceso no puede producirse en el vacío, sólo tiene lugar en un contexto relacional; por tanto, la relación social tiene una estructura (de re-fero y re-ligo), aunque también se manifieste como suceso.

8) Por consiguiente, la relación social siempre implica un contenido normativo. Éste tiene un carácter lógico en el nivel de suposición, mientras que es fáctico en el nivel empírico.

9) No se debe oponer el concepto de relación a los de acción o sistema; la relación es acción recíproca (rel-acción): el sistema es un conjunto organizado de relaciones (a partir de relaciones relacionales); en este sentido, el sistema social es el resultado de la relacionalidad presistémica del mundo social.

10) La relación presupone, al menos, dos entidades en relación: en el caso de lo social, tratándose de acciones, presupone los sujetos que contribuye a conocer en cuanto los expresa e indaga, mientras que, al mismo tiempo, no los (pre)determina; desde esta perspectiva, la relación es un "fenómeno emergente» de sujetos en interacción.

11) Por tanto, la relación es triádica y no diádica. Las consecuencias que se derivan son numerosas; por ejemplo: la ambivalencia sólo es un caso particular de la relacionalidad que está en juego; en los esquemas binarios siempre existe un reduccionismo implícito; en breve, la relación es la «molécula de lo social" (como todos sabemos, la molécula es aquello en que consiste la cualidad específica de una sustancia, en nuestro caso lo social).

Resumiendo, la sociedad es una configuración de relaciones que emergen mediante procesos que analítica y empíricamente pueden diferenciarse en tres fases: las formas socioculturales preexistentes, las acciones de los sujetos agen- 
tes que actúan en relación a los condicionamientos derivados de estas formas, y los resultados de tales interacciones, que pueden ritualizar (morfostasis) o modificar (morfogénesis) las estructuras socioculturales de partida (M. Archer, 1997). El análisis de dichas relaciones sociales implica un tercer punto de vista, ni individualista ni sistémico, que defina el propio objeto como relación y, por tanto, se centre en la relación como realidad y modalidad propia de investigación. La relación es:

- la clave para entrar y salir de la realidad;

- no elimina los términos que liga; al contrario, los investiga y explica;

- un «concreto», no una pura abstracción (forma o comunicación);

- tal conjunto (pensamiento-y-realidad) relacional solamente in extremis es dicotómico (ambivalente, dual, etc.) o confuso: normalmente tiene una estructura de redes, conecta, liga, crea interdependencias; lo que conlleva tensiones y conflictos relacionados;

- las normas (y reglas) son un modo absolutamente necesario e inevitable para regular "normalmente», es decir, en condiciones no extremas, las contingencias de situaciones que, en lo social, no están determinadas a priori.

Si se radicaliza esta perspectiva, de tal manera que la relación deja de ser la clave expresiva de los términos que liga y la vía a través de la que explorarlos, y se convierte en la categoría que los absorbe y anula, entonces se incurre en el relacionismo. Según planteamientos más moderados o más radicales como son, respectivamente, por una parte, el planteamiento fenomenológico (E. Paci, 1965-66), en el que lo social es sinónimo de "vivencia experiencial», y, por otra, las posiciones epistemológicas relativistas (P. Winch, 1958), como la llamada "estética del cambio" (B. P. Keeney, 1983) y la "pragmática relacional» (M. Emirbayer, 1997), el relacionismo puede ser definido como una reducción de la relación a mera vivencia y proceso. En cualquiera de estos casos, aunque de forma diversa, la relación social es presentada como realidad puramente contingente fin en sí misma. Sin embargo, cuando en la sociología relacional que se defiende en estas páginas se dice que los fenómenos sociales son «relativos», se afirma que existen "en relación a»; es decir, se subraya que el carácter "relativo" de un fenómeno social indica una realidad (la relación, con su estructura, funciones, articulaciones) que es unidad de las distinciones y no una pura arbitrariedad o mera situación.

De la relación social no se puede decir lo que Wittgenstein decía del juego lingüístico en el ensayo "De la certeza»: "cualquier cosa de impredecible (...) o sea: no está fundado, no es razonable (o irrazonable). Está allí, como nuestra vida». Que las relaciones sigan reglas vagas, huidizas o ambiguas forma parte de nuestra experiencia cotidiana, así como su tendencia a polarizarse (por ejemplo, en códigos binarios, que es la forma más sencilla de simplificar la realidad). Pero las relaciones sociales no pueden ser estructuralmente inciertas, 
ambiguas o dicotómicas: su objetivo es trasladar más allá de las ambigüedades y de las dicotomías que, sin embargo, ellas mismas generan continuamente.

\section{LA EMERGENCIA DE LA RELACIÓN SOCIAL COMO REALIDAD Y TEMA ESPECÍFICO EN EL MUNDO MODERNO Y CONTEMPORÁNEO}

La perspectiva moderna sobre la relación surge de una nueva conciencia acerca del siguiente hecho: toda operación de distinción (por ejemplo, entre sujeto y objeto, entre res cogitans y res extensa) no es una mera separación categorial, sino que comporta (crea) el problema del relacionamiento (o sea, de nuevas relaciones) entre términos distintos (distanciados). Y así como el conocimiento es — por definición - una continua actividad de distinciones, se puede decir que el conocimiento (y la realidad social) es una incesante creación de relaciones (incluidos los relacionamientos de relaciones). Cuando esta perspectiva, durante mucho tiempo considerada abstracta en cuanto que alejada de las prácticas sociales, adquiera la conciencia de que las operaciones de distinción siempre son producidas y, por tanto, socialmente mediadas (por sujetos que son portadores de una cultura y de un modo de vida), podemos decir que nace el concepto moderno de relación social. Éste se desarrolla siguiendo su propia distinción directriz (es decir: toda distinción es una relación social y toda relación social existe y tiende a desenvolverse según su constitutiva distinción específica).

Por tanto, en primer lugar, la relación social es la referencia de un sujeto a otro sujeto mediada por la sociedad (o por la cultura, los estilos de vida, intereses e identidades) a la que pertenecen los sujetos en relación. En cuanto que la sociedad ofrece lo que es necesario para realizar la mediación (valores, símbolos, reglas, recursos instrumentales), la relación puede asumir modalidades muy diversas.

Pero la relación es algo más que una referencia, simbólica e intencional: también implica "intercambiar algo», una acción recíproca en la que cualquier cosa pasa de ego a alter y viceversa, lo que genera un ligamen recíproco.

Se ubica aquí la idea de que el intercambio es el núcleo y el motor que impulsa las relaciones sociales. Aceptar esta perspectiva implica no reducir el intercambio a mera categoría económica, ya que todo intercambio posee una estructura interna compleja y articulada en diversas dimensiones, irreducibles entre sí, como los valores, las normas, las finalidades y los medios que utiliza. Las relaciones contempladas como intercambio pueden construirse en todas aquellas formas en que es posible configurar el tránsito de algo entre los polos o sujetos de la relación con la creación de una nueva entidad o situación. La sociedad moderna puede ser interpretada como descubrimiento y construcción de esta perspectiva. En un primer momento, dentro de unos horizontes limitados; con posterioridad, en un sentido progresivamente más generalizado (P. Donati, 1998: 21-22). 
Normalmente, se suele representar el nacimiento de la sociedad moderna como emergencia de las relaciones de Gessellschaft (relaciones contractuales y asociativas de mercado, entendidas como expresión de voluntad arbitraria y de intereses finalizados en objetivos instrumentales), frente a las relaciones de Gemeinschaft (relaciones tradicionales de comunidad, entendidas como expresión de voluntad esencial y de ligámenes adscriptivos) (F. Tönnies, 1947). La Gemeinschaft es la relación social propia (normal) de la "vida real y orgánica», mientras que la Gessellschaft es la relación social propia (normal) de las «formaciones (sociales) ideales y mecánicas». La sociedad moderna es, por excelencia, aquella que privilegia las "relaciones asociativas» sobre las "relaciones comunitarias».

Indudablemente, esto es exacto. Sin embargo, es necesario insistir en el carácter no pura ni prevalentemente económico de tal transformación. Aun teniendo un carácter relacional, mientras distingue, conecta y hace interactuar entre sí los diversos componentes internos de las relaciones sociales, en concreto aquellos motivacionales, adaptativo-funcionales y de representación cultural. Diversos autores han puesto de manifiesto cómo las matemáticas, el álgebra y, en general, los modernos sistemas informáticos han nacido de las exigencias prácticas insertadas en las relaciones sociales de intercambio activadas por los mercaderes (los burgueses) que han dado vida al capitalismo occidental (R. W. Hadden, 1988). Pero no se debe olvidar que no se podrían haber instaurado nuevas razones de intercambio sin que hubiesen estado disponibles nuevos modos culturales de pensar y obrar las relaciones sociales en sentido más amplio (detrás de este aspecto se esconde la minusvaloración de las aportaciones de las llamadas escuelas «escolásticas» al debate sobre la categoría filosófica de la relación entre el 1200 y el 1500 en toda Europa).

Adoptando esta óptica, algunos autores han mostrado cómo las grandes reformas religiosas y las transformaciones del sistema social, económico y político en los inicios de la época moderna han sido el producto de una "retórica de las relaciones sociales» (entendida como modo de pensar y de discurrir) que ha producido un contexto de relaciones sociales capaz de trascender el orden societario precedente (por ejemplo, sobre los procesos que han trasladado a la formación del Estado y de la Iglesia nacional en Inglaterra entre 1540 y 1640) (P. Bearman, 1993).

Brevemente, se puede decir que la relación social emerge como realidad y como tema específico de investigación con la sociedad moderna si y en la medida en que se verifican dos grandes fenómenos:

a) Primero, las relaciones entre las personas $-y$, en general, entre los actores que se mueven en la sociedad - no son ya vistas y vividas «como dadas por naturaleza», sino que son consideradas como históricas; por tanto, como mutables, producibles y reproducibles según modalidades culturales de tipo «artificial». La distinción entre lo que caracteriza las relaciones sociales de intercambio del "hombre moderno" y lo que connota las relaciones naturales y 
adscriptivas del "hombre premoderno" camina al mismo paso que la emergencia de aquella esfera social, caracterizada por las nuevas instituciones de la opinión pública burguesa y del mercado capitalista, en las que y a través de las que se cumple el gran experimento del progreso en sentido moderno.

b) Segundo, desde el punto de vista del pensamiento reflexivo, la categoría filosófica y cultural de relación no es ya considerada como simple y axiomática (un a priori y una categoría primera de la mente), sino que -en cuanto aplicada al vivir social — se la representa como una noción compleja y articulada según diversas modalidades culturales. Afirmar que la relación social pueda ser interpretada (semantizada) comporta la posibilidad de someterla a un universo de códigos simbólicos que, a su vez, están sujetos a varias formas evolutivas. En cualquier caso, la noción de relación social asume una tensión interna, se presenta ambivalente y diferenciable (tanto interna como externamente), según componentes y dinámicas que deben ser explicados una y otra vez.

Estos dos grandes desplazamientos en el modo de entender la relación social indican que la modernidad —observada como forma cultural — está caracterizada por la idea de que la civilidad de una sociedad (su connotación de "civil») está estrechamente ligada a la cantidad y cualidad de las relaciones que vienen creadas mediante un proceso de diferenciación social. Éste, a continuación, genera, destruye y reorganiza las relaciones sociales según diversas distinciones-guía que actúan en las diversas esferas, subsistemas o contextos de la sociedad (por ejemplo, las relaciones de intercambio a partir de un precio poseen una distinción-guía diferente de las relaciones de amistad, sexuales o íntímas, y estas últimas de las distinciones-guía que caracterizan las relaciones profesional-cliente, médico-paciente, maestro-discípulo, etc. $)^{4}$.

${ }_{4}^{4}$ Según P. Donati, el proceso de diferenciación se activa mediante una utilización auto y heterorreferencial de la relación. Por este motivo, la perspectiva relacional desarrollada por el sociólogo italiano pone de manifiesto la unilateralidad de los planteamientos auto y heterorreferenciales. La relación es autopoiética en cuanto que se genera a sí misma, en el sentido de que sigue la propia distinción directriz (ejemplo: la relación médico-paciente debe desarrollarse según la propia intencionalidad médica). La autopoiesis requiere relacionamiento, pero se trata de un relacionamiento activado por parte de un sistema que se autodiferencia autorreferencialmente (en el ejemplo de la relación médico-paciente, se deben excluir todas aquellas relaciones que no tengan finalidad médica). Sin embargo, la relación también es generación de novedades mediante la referencia a otras relaciones y la conexión con ellas (siempre teniendo presente la relación médico-paciente, se deben buscar las referencias a otras relaciones que puedan ser significativas para la relación médica). En consecuencia, constituye un error pensar la relación sólo como referencia auto o heteropoiética (P. Donati, 1998: 25). 


\section{DIVERSAS APROXIMACIONES AL ESTUDIO DE LA RELACIÓN SOCIAL 5}

Casi todos los autores modernos y contemporáneos hablan de relaciones sociales. Por tanto, no resulta aventurado decir que la relación social ocupa un puesto preminente en las Ciencias Sociales. Sin embargo, esta afirmación debe ser matizada. En contadas ocasiones se ha presentado a la relación social como una clave esencial y un foco de lectura de los fenómenos sociales, es decir, en el sentido de elaborar una específica Ciencia Social como «teoría de las relaciones sociales» diversa de una simple tipología (más o menos compleja y articulada) o de un producto indirecto de otras teorías (por ejemplo, de la acción, o de las formaciones sociales, o del sistema social, etc.).

Posiblemente, la mayor dificultad deriva del siguiente hecho: no es fácil tematizar a la relación social en sí y aún sigue siendo estudiada desde perspectivas muy particulares o de forma derivada. Dicho en otros términos, las diversas aproximaciones al estudio de la relación social han puesto de manifiesto algunos aspectos y propiedades conforme a sus premisas generales y sus métodos y objetivos particulares. En general, se ha tratado de definir la relación social como un objeto entre tantos de las Ciencias Sociales (como los grupos, las clases, etc.). El resultado ha sido acentuar sus connotaciones sociopsicológicas como modo de ser y de obrar intermental (desde G. Tarde a las variadas escuelas norteamericanas de derivación meadiana), antes que analizarla como contenido y constitutivo de lo social, en sentido tanto estructural como simbólico.

A continuación trataré de analizar estos diversos planteamientos y, posteriormente, si es posible, los articularé en una visión comprensiva de la relación social. El objetivo es poner de manifiesto cómo, a lo largo de la historia de la sociología, existen autores que han hecho de la relación social un objeto significativo, pero no un foco en sí mismo. Ahora bien, al exponer estos paradigmas se debe tener presente que se recurre a una síntesis que, en buena medida, limita el pensamiento de determinados autores.

3.1. El planteamiento marxista: la relación social como producto de las bases materiales (económicas y cientifico-técnicas) de la sociedad. Karl Marx (18181883) adopta una perspectiva relacional sobre la sociedad, sus actores, estructuras y procesos. Pero, desafortunadamente, nos encontramos ante una visión reductiva. En ella, el hombre es un ser puramente social en cuanto ser determinado por las relaciones materiales (por ello llamadas relaciones sociales) en las que se encuentra históricamente (cfr. Tesis sobre Feuerbarch, 1845). Esta perspectiva es desarrollada de forma mucho más clara y concreta en los Grundrisse. El autor se propone mostrar cómo la sociedad no está hecha de individuos,

5 Al elaborar este apartado he seguido como guía buena parte de las argumentaciones y planteamientos expuestos por P. Donati (1986: 237-243). 
sino que expresa el conjunto de ligámenes y relaciones en los que están insertados los propios individuos (en buena medida, ésta es la base del estructuralismo sociológico).

Las relaciones sociales se conciben en sentido sustancial según un realismo absoluto materialista — de fondo económico — que las presenta: a nivel micro, como condicionamientos concretos que se unen en un cuerpo biológico dotado de un aparato psíquico capaz de absorberlos y reelaborarlos; a nivel macro, como relaciones entre clases sociales determinadas por la propiedad de los medios de producción y por el nivel de las fuerzas tecnológicas.

Un ejemplo de definición relacional es el concepto de "capital» que nos presenta Marx. Éste no es definido como una entidad material (mueble o inmueble) en sí ni como una entidad subjetiva, sino como una relación social, aquella de apropiación de los medios operada por el capitalista en perjuicio de los productores. Más concretamente, Marx rechaza la definición de "capital» como dinero o patrimonio económico de cualquier género, o sea, como "cosa», y propone definirlo como relación social de explotación.

Nos encontramos ante el primer ejemplo sociológico, de enorme trascendencia, que plantea la redefinición relacional de un objeto en las Ciencias Sociales modernas. Sin embargo, aunque Marx ofrece una teoría de las relaciones mediadas a través de la forma de la mercancía (ésta es presentada como un campo de interacciones que tan sólo son el aspecto activo, práctico, de las relaciones), no camina hacia una teoría completa de las relaciones sociales, ni de las concretas ni de las generalizadas. El no desarrollo de esta teoría debe ser imputado al hecho de que la epistemología del materialismo histórico no tiene debidamente en cuenta los aspectos culturales y subjetivos de las relaciones sociales e impide la elaboración de un aparato suficientemente analítico para producir generalizaciones válidas. Es decir, la adopción de una posición esencialmente historicista impide la elaboración de una teoría analítica generalizada ${ }^{6}$.

Algunos autores marxistas, en concreto A. Gramsci y los neomarxistas, atribuyen mayor valor (autonomía) a los componentes simbólicos (siempre vistos como ideología) de las relaciones sociales. De esta manera limitan el determinismo causal de los fenómenos sociales, que pasan a ser explicados como interacción entre las dimensiones culturales y materiales de las relaciones sociales.

En cualquier caso, a pesar de posteriores desarrollos, el planteamiento marxista sigue vinculado a su intrínseca connotación materialista y estructuralista. Un buen ejemplo son las aportaciones de L. Althusser y P. Bourdieu. Este último (P. Bourdieu, 1992) expresa un particular relacionismo ontológico y meto-

${ }^{6}$ Desde una perspectiva más amplia se puede decir que, en la identificación de sus objetos de investigación, Marx opta por la vía de definirlos en términos de relaciones sociales como resultado y expresión de factores materiales (según el nivel y cualidad de las fuerzas productivas) que les hacen asumir una determinada configuración, es decir, que los determinan en formas históricas concretas. 
dológico de origen marxista que es clave en las nociones y estrategias de investigación que elabora ${ }^{7}$. En su opinión, la sociedad es una noción vacía, por lo que es necesario sustituir un espacio socialmente estructurado en el que los agentes (no reducibles a una única lógica societaria) luchan en función de la posición que ocupan, obligados a la configuración de un sistema estructurado de fuerzas objetivas que impone determinadas relaciones, en general de conflicto y competencia, con el fin de establecer un monopolio sobre el peculiar capital en el que se actúa (la autoridad cultural en el terreno artístico, la autoridad científica en el terreno científico, la autoridad sacerdotal en el terreno religioso, etc.) y sobre el poder de decretar la jerarquía entre las diversas formas de autoridad en el campo del poder. Aunque Bourdieu trate de escapar al rígido determinismo clásico, la creatividad de los agentes tiene para el sociólogo francés grandes límites en sus hábitos (que son mecanismos estructurantes) y las relaciones encuentran barreras insuperables en las estructuras del campo del espacio social, así como la voluntad y la intencionalidad subjetivas están disminuidas.

\subsection{El planteamiento positivista: la relación social como modelo estructura-} do de la conciencia colectiva. Émile Durkheim (1858-1917) presenta la teoría sociológica positivista de mayor relieve sobre las relaciones sociales. Nos encontramos ante una formulación de la sociedad (como relación social) que la concibe como si se tratase de una realidad materialmente emergente de las relaciones entre singulares individuos («privados») que dan vida a una fuerza colectiva ${ }^{8}$.

En una primera época ve la relación social emergiendo de la división social del trabajo. Es el punto de partida de la célebre distinción entre "solidaridad mecánica», que consiste en relaciones entre sujetos uniformes (típica de las sociedades simples, arcaicas y tradicionales, de mínima división del trabajo), y "solidaridad orgánica», que consiste en relaciones entre sujetos siempre más individualizados y diferenciados (típica de las modernas sociedades industriales con elevada y creciente división del trabajo). Sucesivamente, Durkheim profundiza en el contenido y caracteres simbólicos de la relación social, entendiéndola como expresión de la "conciencia colectiva». Suya es la siguiente argumentación: lo social es todo aquello que, teniendo capacidad de integración, se

Muy buenos ejemplos son las nociones de habitus y de campo, definidas como «nudos de relaciones»: el primero - habitus - aparece como un conjunto de relaciones históricas «depositadas» en cuerpos individuales bajo la forma de esquemas mentales y corpóreos de percepción, de valoración y acción; el segundo — campo- es concebido como un conjunto de relaciones objetivas históricas entre posiciones ubicadas en ciertas formas de poder o de capital (P. Castón, 1996: 81-87).

8 «Sin duda — dice Durkheim-, cada uno contribuye a la elaboración del resultado común; pero los sentimientos privados solamente se hacen sociales encontrándose con la acción de las fuerzas sui generis producidas por la asociación: por efecto de estas combinaciones y de las alteraciones reciprocas que emergen, se hacen algo diferente. Se verifica una sintesis quimica que concentra y unifica los elementos sintetizados, y por ello los transforma» (E. Durkheim, 1976: 159). 
configura como «ligamen», y siendo la religión (de religo, «asociar conjuntamente») el mayor elemento integrativo, deberá existir una correspondencia plena entre sociedad y religión. Por tanto, no resulta arriesgado decir que, para Durkheim, la relación social, en cuanto ligamen, vendrá a asumir las características de lo «religioso».

Con ello, el positivismo durkheimiano ilumina el carácter normativo de la relación social como elemento autónomo del espacio social. Ahora bien, en Durkheim, al concebir la relación como un vínculo y un condicionamiento (una realidad externa y coercitiva) entre los individuos, la relación individuo-sociedad mínimamente es tematizada como acción recíproca (rel-acción) (como posteriormente dirá Parsons, en el proceso de socialización se interiorizan las relaciones y no los objetos sociales...). Famosa es la polémica con G. Tarde (1843-1904). Este último sostenía que mientras la psicología estudia las relaciones existentes dentro de la mente entre creencias, deseos, necesidades y principios morales, la sociología estudia las relaciones entre las mentes que permiten transmitir los mismos fenómenos de un individuo o grupo social a otro. Tarde subdivide las relaciones sociales en tres tipos: relaciones de imitación (o repetición), de oposición y de adaptación. Para este autor, los fenómenos sociales se difundían mediante la imitación, teniendo lugar las innovaciones con la adaptación. La lucha entre adaptación e imitación producía las formas de oposición (G. Tarde, 1895, por muchos considerado uno de los fundadores de la concepción psicológico-social de la relación). Por su parte, Durkheim observa que las relaciones sociales no se convierten en elementos constitutivos de la sociedad por el simple hecho de repetirse, y menos a través de la imitación, sino porque están "prescritas» por la colectividad, es decir, por el carácter coercitivo que poseen (contrainte social).

En breve, Durkheim presenta una teoría fuertemente holista e integrativa de las relaciones sociales, que, al mismo tiempo, pone de manifiesto el carácter simbólico (como referencia a la «conciencia colectiva») y estructural (como ligamen) autoproducido por la sociedad. Éste será el nacimiento de la escuela francesa (en la que se enmarcan autores como M. Mauss y C. Lévi-Strauss) que concibe las relaciones sociales como estructuras connotativas de la sociedad entendida como orden colectivo de intercambios a través de los que se genera y se regenera el tránsito de la naturaleza a la cultura. Una escuela totalmente opuesta a los planteamientos individualistas desarrollados al otro lado del Atlántico por autores como G. Homans o P. Blau (P. P. Ekeh, 1974).

Aunque la sociología durkheimiana constituye uno de los fundamentos de la visión funcionalista de las relaciones sociales (en Durkheim las relaciones no tienen finalidad, sólo son funciones), hay que puntualizar que la visión de este autor contempla en las relaciones sociales algo más que un puro funcionalismo. Para Durkheim, las relaciones sociales asumen determinadas funciones (que sólo pueden ser comprendidas cuando están conectadas a determinadas estructuras), pero dichas relaciones siempre son suprafuncionales, según la terminología utilizada por G. Gurvitch (1950). Es decir, no asumen un número 
discreto y limitado de funciones, sino que realizan una serie no numerable de funciones (manifiestas y latentes), que constituyen el fundamento de toda sociedad, incluso a través del conflicto.

3.3. El planteamiento histórico-comprensivo: la relación social como proyección del sujeto individual. Max Weber (1864-1920) tematiza la relación social de otro modo. En primer lugar, porque explica el carácter intencional e intersubjetivo (antes que estructural, impersonal o bien suprapersonal) y, posteriormente, porque escoge explícitamente la categoría de la relación social como noción central del propio programa de investigación. Más explícitamente, retiene que la relación social es el constitutivo "fundante» del tejido social, o bien de las formaciones sociales?.

Weber elabora una definición que puede considerarse clásica:

"Por relación social se debe entender un comportamiento de diversos individuos instaurado reciprocamente según su contenido de sentido, y orientado en conformidad. Por tanto, la relación social consiste exclusivamente en la posibilidad de que se obre socialmente de un modo determinado (dotado de sentido), que sea la base en la que descansa tal posibilidad» (1964: vol. 1, 23-24).

El planteamiento weberiano es el origen de todas las sociologías de la acción o "accionistas». Recibe el calificativo de comprensivo porque confía al investigador social el objetivo no de "explicar» los comportamientos mediante relaciones causales (ya que las acciones son una mera posibilidad, no siguen líneas causales predefinidas), sino de "comprenderlos» en cuanto expresiones de actores que se orientan recíprocamente a partir de un sentido simbólico que, aunque requiera conformidad, viene interpretado subjetivamente.

La idea fundamental de Weber es que prácticamente todos los objetos de la sociología puedan y deban ser definidos como "complejos de relaciones sociales», desde el grupo informal a la clase social, desde el partido político al Estado y la Iglesia... (J. Freund, 1990). Recuerdo que ésta es una de las bases del análisis funcionalista

Sin embargo, tampoco Weber elabora una teoría analítica suficientemente

9 Este planteamiento también nos aparece en Tarde. No en vano, el pensador francés había propuesto considerar como objeto más elemental de la sociología no al individuo, sino a la pareja o diada, desde la cual emergerían todas las formaciones sociales de orden superior tales como la familia, la comunidad o la nación. Sin embargo, Tarde contemplaba la relación como entidad intermental y, según Weber, esto no es suficiente. Este último observa la relación como concretización histórica a partir de los grandes sistemas simbólicos. Como posteriormente se verá, también Simmel escoge fundar su sociología sobre la relación social. Ahora bien, el programa simmeliano está basado en la idea de separar la forma del contenido de la relación, mientras que Weber sostiene que se debe mantener la conexión concreta, histórica, entre forma y contenido de las/en las relaciones sociales, sabiendo que las abstracciones formales —incluidos los tipos ideales- son puras convenciones. 
generalizada de la relación social, bien sea debido a las fuertes connotaciones historicistas (analizar sólo las concretas relaciones existentes), bien sea debido a las insuficiencias metodológicas (su llamado «individualismo metodológico» no permite, al final, observar las relaciones como tales) (J. Alexander, 1983: vol. III). La comprensión que los sujetos tienen de sus relaciones (es decir, su obrar teniendo presentes a los otros) es siempre un problema, y mayor problema es la comprensión que puede alcanzar el estudioso que observa los fenómenos sociales como productos de los sujetos individuales agentes ${ }^{10}$. Esto ha derivado en la creación de corrientes postweberianas. Algunas acentúan la interpretación «subjetiva» de la relación social. Otras tratan de fundamentar la comprensión de la relación en la categoría del «mundo de la vida», entendido como mundo simbólico de la vida cotidiana dado-por-descontado (prerreflexivo). El denominador común ha sido evitar los giros en clave subjetivista y contingentista insertados en este planteamiento. En cualquier caso, el planteamiento weberiano se convertirá en una componente importante de la teoría de las relaciones en la sociología de Talcott Parsons (donde ocupa el lugar de las motivaciones psicoculturales, o el eje L-G en el esquema AGIL) y de N. Luhmann (que trata la relación en términos de sentido comunicativo y de meras posibilidades) (P. Donati, 1998: 31-32).

\subsection{El planteamiento formalista: la relación social como forma fundamental} de la conexión hombre-hombre. Como Weber, también Simmel (1858-1918) concentra todo su esfuerzo en la elaboración de una específica sociología entendida como teoría de las relaciones sociales. Pero matizemos: la desarrolla en un sentido totalmente opuesto a los autores precedentes, es decir, en clave puramente formal. El programa teórico de Simmel consiste en elaborar una sociología que se relacione con lo social de igual manera a como la geometría se relaciona con la realidad física: se trata de investigar la sociedad como campo de relaciones que pueden ser extraídas en "formas puras», es decir, prescindiendo de sus contenidos.

El tema fundamental de Simmel es que "la sociedad es reciprocidad entre individuos», o sea, que lo social es el efecto emergente de la reciprocidad o intercambiabilidad de las acciones (Wechselwirkung). Las relaciones son analizadas como formas elementales del puro "estar juntos» (sociabilidad), allí donde la sociabilidad es entendida como aspecto estético del relacionarse recíproco (en breve: la sociabilidad «representa» la realidad social, así como el arte "representa» la naturaleza).

En este planteamiento se prescinde del contenido vital que está tanto en los sujetos como en las concretas motivaciones y cualidades de las relaciones en cuanto entidades históricas situadas en el aquí y ahora, y se realiza una abstracción geométrica (otros dicen gramatical) del puro ser social entendido como el puro "ser entre», "ser con», "ser sin». Como más tarde dirá L. von Wiese, reto-

${ }^{10}$ En esta línea se sitúan las posteriores notas críticas de A. Schütz. 
mando la idea formalista de este programa, "la sociología general tiene el objetivo de descubrir lo humano en sí y por sí, en aquello por lo que es interpersonal» (1955: 273). La relación social se convierte en el objeto de la sociología en cuanto forma fundamental de la conexión hombre-hombre, el «puro interhumano» desligado de los vínculos, por una parte, con las esferas objetivas de la vida económica, política, jurídica, etc., $y$, por otra, con los motivos subjetivos individuales ${ }^{11}$. El campo relacional es visto como un campo de fuerzas cargado de energías, no reducibles a líneas de enlace rígidas e invariables. Mediante los retículos de las relaciones sociales, los hombres están ininterrumpidamente aproximándose los unos a los otros, o alejándose los unos de los otros: "ante la pregunta ¿qué es una relación social? se puede responder: es un estado labil ocasionado por un proceso social o (más frecuentemente) por más de un proceso social en el que los hombres están reciprocamente ligados o separados. Dicho brevemente, y por ello con ciertas posibilidades de error, una relación social es una determinada distancia entre ellos» (1955: 276).

Los tipos generales de la relación se evidencian confrontándolos con los dos principales procesos de la vida social:

a) los procesos A (asociativos), que consisten en los estados de la sociabilidad y de la conexión, por una parte, y de la dependencia, por otra;

b) los procesos B (disociativos), que, por una parte, trasladan a la soledad y al retiro y, por otra, a la independencia (1955: 379).

Para este planteamiento la sociología es un estudio de las relaciones, pero éstas sólo son concebidas como intersecciones de líneas entre varios puntos (los individuos) que se aproximan o se alejan, se integran o introducen conflicto, que se diferencian según círculos concéntricos e intersecantes. La relación social no es una clave para comprender los fines, los valores y los objetivos a partir de los que tiene lugar el proceso social (y mediante los que actúan las instituciones sociales); más bien es un gráfico que permite entender en qué posición están los diversos puntos entre sí en las formas más generales de los "juegos de las sociedades». A partir de estas bases vienen elaboradas diversas tipologías: de manifestación de la sociabilidad, por ejemplo los tres tipos de rapport avec autrui de G. Gurvitch (1950: cap. III), que derivan de la teoría wiesiana de los procesos de proximidad y distancia.

3.5. El planteamiento fenomenológico: los componentes intersubjetivos de la relación. La fenomenología de E. Husserl (1859-1938) es el fundamento de un

11 "Está claro - afirma Wiese-que una esfera de la vida inter-relacionada, en la que no existen autonomias, no puede representar más que un ámbito de innumerables relacionamientos e intersecciones. Esta esfera se representaria gráficamente como una red aparentemente impenetrable de lineas, que parten desde puntos (los hombres), que se encuentran en los extremos del campo. Se trata de ordenar este retículo y de explicar cómo estos innumerables relacionamientos hacen posible una vida civil (en el sentido más amplio del término)»(1955: 275). 
planteamiento, desarrollado por autores como A. Schütz, P. Berger, Th. Luckmann, que define la relación social como "conexión intersubjetiva de motivos» (A. Schütz, 1962: 341). Desde el perfil filosófico y psicológico, la relación observada (dada) inicialmente es situada «entre paréntesis» (epoché) para posteriormente ser reconstruida como operación intersubjetiva del yo trascendental (E. Husserl, 1962). Obviamente, esto supone enormes problemas de reconstrucción, hasta el punto de que alguno ha observado la imposibilidad de la fenomenología de ofrecer una explicación de la sociedad como tal, es decir, como relación no dependiente totalmente de la subjetividad ( $\mathrm{R}$. Toulemont, 1962). Dicho en otros términos, es imposible reconstruir las relaciones teniendo como único punto de partida los sujetos individualmente observados, incluso si se los considera orientándose recíprocamente (intersubjetividad).

Desde el perfil sociológico, este planteamiento estudia el carácter recíprocamente subjetivo de la relación social, limitando los condicionamientos estructurales a lo que vincula a los agentes en cuanto "mundo-ya-dado» (cultura transmitida, mundo de los predecesores, realidad externa circundante, etc.). La dimensión estructural (de ligamen) de la relación social no es considerada un hecho constitutivo de esta última. El análisis se centra en la construcción del mundo social como mundo dotado de sentido por los sujetos que desarrollan la experiencia mediante una intersubjetividad basada en la relación-del-nosotros (we-relation) (L. Muzzetto, 1997).

La estructura del mundo social viene interpretada como construcción de un mundo intersubjetivamente significante (donde los mismos significados son realidades relacionales). Como dice Ludovido Actis Perinetti: «si el designatum del discurso no es puramente, como para Wittgenstein, un hecho entendido aisladamente que puede ser afirmado o negado, sino que es el mismo hacerse de una relación de experiencia, que mientras cambia se aclara expresivamente a sí misma, cae la no justificada antonomia entre semanticidad y libre expresividad, es decir, entre el significar objetos y abandonarse a la creatividad de la fantasia" (1959: 48).

Tesis central es que no se pueden comprender las relaciones sociales generalizadas (de segundo nivel, abstractas, formalizadas, como las institucionalizadas) si no se comprenden las relaciones de primer nivel (las acciones intersubjetivas en el mundo de la vida), siendo estas últimas la base (lo constitutivo) de las instituciones y del sistema social entendido.

El planteamiento posee una intrínseca tendencia a la subjetivización (aunque colectiva) de las relaciones sociales. En este sentido es consciente de encontrar algunos límites en el desarrollo de un análisis de tipo macroestructural. Concretamente, en la visión relacional de Schütz son evidentes las influencias del psicologismo del filósofo pragmático W. James y una cierta tendencia al nominalismo formalista.

3.6. El planteamiento del interaccionismo simbólico: la relación social como interacción y mediación simbólica. Nace en los años veinte en el campo de la 
psicología social y de la mano de G. H. Mead. Su introducción en la sociología tiene lugar a través de la epistemología genética de J. Piaget. Como el precedente, este planteamiento no ofrece una teoría sistemática de las relaciones sociales; más bien es un "acercamiento", un modo de observar y entender la realidad social a través de algunos conceptos e instrumentos expresamente definidos. Sin embargo, sitúa en su núcleo un principio que está en la base del análisis relacional. Según tal principio, "el todo social no es una reunión de elementos anteriores, ni una nueva entidad; al contrario, es un conjunto de relaciones, cada una de las cuales genera - en cuanto relación-una transformación de los términos que liga» (J. Piaget, 1964: 26, 55).

La relación social es considerada como interacción, es decir, como una acción entre dos agentes en la que es central la mediación simbólica que uno ejerce sobre el otro, en cuanto que se supone que la representación de sí mismo (self) tiene necesariamente lugar a través del otro (alter) (G. H. Mead, 1934). Relación social significa: cómo nosotros convertimos los sí mismos (selves) a través de los otros (G. H. Mead, 1977: cap. 2). Toda relación es una realidad en sí (Piaget la llama «totalidad») que transforma los individuos (términos) participantes a partir de su estructura mental. Desde la interacción entre dos individuos hasta el sistema («totalidad») construido por el conjunto de relaciones entre los invididuos de una misma sociedad, estamos ante una continuidad por complejidad creciente que no cambia la esencia del fenómeno social ni requiere instrumentos diferentes de análisis. La parte débil de este planteamiento consiste en asumir un elemento, lo simbólico, como clave explicativa totalizante y no como foco de análisis, que, aunque rico y fecundo, resulta ser parcial.

Emparentado con la fenomenología y el interaccionismo simbólico, nos encontramos con el planteamiento etnometodológico ${ }^{12}$. Aunque con diversos métodos, estudia las relaciones de la vida cotidiana como expresiones de juegos sobre la distancia social o bien como asunción de rol (role-taking) que no es mera conformidad, sino modificación del rol social en el acto mismo en que se asume (role-marking). A pesar de analizar los comportamientos, los gestos expresivos y las estrategias de los actores individuales, el foco del análisis no se sitúa en los sujetos (lo social no es una manifestación de la personalidad individual), sino en el peso normativo de la sociedad, es decir, en las formas en que la sociedad introduce el propio "dedo regulativo» en las relaciones. El individuo es visto como un jugador, un sintetizador entre las múltiples relaciones que lo ligan a los diversos círculos sociales. Por tanto, las relaciones son consideradas como manifestación de una vida cultural, concebida como constituida por reglas de comportamiento y acuerdos normativos en situaciones con diversos contenidos de riesgo, que se encarna en estructuras sociales (E. Goffman, 1974) ${ }^{13}$. Especial

12 Entre las figuras más sobresalientes habría que destacar autores como H. Garfinkel (1967), E. Goffman (1967, 1969) y A. Ardigo (1980).

13 Un interesante estudio desde esta perspectiva sobre la sociedad china puede encontrarse en Y. Shuo (1993). 
atención se da al "ritual de la interacción» (juegos de cara, diferencia y conducta, juego de azar, etc.) o bien a la relación entendida como "interacción estratégica» en que los actores se comportan como agentes de espionaje comprometidos en descubrir los secretos de los adversarios, en un ciclo potencialmente infinito de simulaciones, descubrimientos, falsas revelaciones y redescubrimientos...

3.7. El planteamiento estructural-funcionalista: la relación social como acción reciproca de actores en un sistema social. En algunas ocasiones ha sido interpretado como un planteamiento puramente metodológico. Sin embargo, sus pretensiones son desarrollar una verdadera y propia «teoría sociológica» que sea capaz de superar los límites de la investigación empírica. En concreto, más que ningún otro planteamiento, se propone elaborar una teoría general sistémica de la relación social. Tiene como punto de partida un postulado que condiciona todos los desarrollos posibles en términos de observación y reflexión: la relación (social) es considerada como función (social). En otros términos, la relación no es sino el modo en el que el sistema social, o sistema de acción, funciona; la relación es la expresión de un obrar en un estatus-rol, dentro de un sistema de estatus-roles.

A lo largo de toda su obra, T. Parsons asume que la propiedad más general y fundamental de todo fenómeno social (considerado como sistema de acciones) es la relacionalidad constitutiva de sus partes, dimensiones o variables. La interdependencia que sustenta tal relacionalidad consiste en la existencia de determinadas relaciones entre las partes o variables, en contraste con la variabilidad causal. En otras palabras, la relación es interdependencia (con interpenetración), y la interdependencia es tanto el orden en las relaciones entre los componentes que entran en un sistema como su efecto emergente. "Los sistemas de acción —afirma Parsons (1937: 739)— tienen propiedades que sólo emergen en un determinado nivel de complejidad en las relaciones de las singulares acciones elementales (unit act) las unas hacia las otras. Estas propiedades no pueden ser identificadas en toda singular acción elemental considerada separadamente de sus relaciones con las otras en el mismo sistema. No pueden ser derivadas de un proceso de generalización directa de las propiedades del acto elemental.»

Desde este punto de vista se contempla la realidad sui generis de la relación social, que consiste en el generar los «efectos estructurales» (entendidos como comportamientos de conformidad no interiormente compartidos por los actores individuales) (P. Blau, 1960) y los llamados "efectos perversos» (entendidos como efectos no intencionales producidos por una multitud de singulares acciones intencionales) (R. Boudon, 1981). Consiguientemente, se puede observar por qué los planteamientos individualistas, tanto los instrumentales como los idealistas o normativos, son empíricamente incapaces de aclarar las relaciones causales de la vida social.

En síntesis, Parsons ha establecido algunas bases fundamentales para un 
planteamiento relacional comprensivo, integrado y multidimensional, aunque posteriormente no ha desarrollado coherentemente tal proyecto ${ }^{14}$.

\subsection{El planteamiento neofuncionalista comunicativo: la exaltación de la} relación social como pura comunicación. El funcionalismo sistémico postparsoniano ha abandonado la idea de mantener todo el espesor, o sea, la forma y contenido, dimensiones estructurales y accionistas, de las relaciones sociales y decisivamente se ha orientado a tratar la relación social como pura función comunicativa. La operación, ya adelantada por una serie de autores norteamericanos (expresiones de las corrientes de estudio sobre la ecología de la mente, de la pragmática comunicativa y de las nuevas ciencias informáticas y cognitivas: G. Bateson, M. McLuhan, P. Watzlawick, H. von Forester y otros), ha sido llevada a sus máximas consecuencias en Europa por N. Luhmann. Éste la ha injertado en la nueva biología de F. Varela y H. Maturana, mediándola a través de la lógica de G. Spencer Brown.

En este planteamiento la relación viene equiparada a la comunicación, entendida como operación específica de los sistemas sociales que consiste en la síntesis (o unidad de la diferencia) de tres selecciones (emisión, información y comprensión de la diferencia entre emisión e información). Al ser entendida la comunicación como suceso (desaparece nada más aparecer), y en cuanto que la comunicación sólo tiene el sentido de ligarse con otra comunicación (en esto consiste el proceso social), las relaciones sociales pierden consistencia, estabilidad y orden prefijado. La relación social ya no es un conductor de significados culturales predefinidos, ni un canal preestructurado para la transferencia de informaciones y prestaciones. Hablar de relaciones sociales en clave neofuncionalista es equivalente a observar comunicaciones sobre comunicaciones que siempre trasladan a otras posibilidades de experiencias vitales funcionalmente similares y, por tanto, intercambiables. Esto deriva en: la relación social pierde su «dureza», estratificación y "consistencia» sociológica, especialmente aquella estructural y normativa.

\subsection{El planteamiento hermenéutico: los componentes dialógicos, normativos} $y$ hermenéuticos de la relación social. En esta denominación podemos recoger una amplia y diversificada corriente de pensamiento que, en las Ciencias Sociales modernas, trata la relación social como diálogo. Lo que aglutina a estos pensadores es el siguiente hecho: para ellos, decir relación social significa referirse a la vida social en cuanto discurso entre sujetos en los que es fundamental la elaboración cultural que nace mediante el lenguaje y la conversación.

Con el término Beziehung, M. Buber indica exclusivamente la relación dialógica yo-tú (de plena interpenetración interhumana), frente a la relación yo-él (que es la experiencia objetivizante, "cosificante» del otro»): "la palabra funda-

${ }^{14}$ Los límites y contradicciones del planteamiento parsoniano han sido puestos de manifiesto por J. Alexander (1983: vol.IV) y P. Donati (1991: 50-52). 
mental yo-tú funda el mundo de la relación» (1923: 61). Según Buber, las dos vías puestas en práctica por el hombre contemporáneo para superar la propia crisis (la «soledad social»), es decir, el individualismo y el colectivismo, no conducen a ninguna salida. La vía auténtica es la de la relación «entre-hombre-yhombre», de la relación interpersonal y de la comunidad. Sólo en la relación con el "otro" hombre el individuo se encuentra a sí mismo, al tiempo que supera la soledad y el aislamiento: sólo en el encuentro con el otro, en la relación establecida entre (zwischen) el yo y el tú, el hombre entra en la auténtica realidad, de la cual se había alejado. Con un planteamiento de clara inspiración religiosa (hebraico) pero con evidentes implicaciones sociológicas, Buber sostiene que la comprensión del problema del hombre no debe concentrarse en el individuo, sino en el «entre», es decir, en la relación. El motivo es bien sencillo: sólo en ella el hombre se constituye como persona, o sea, como un "yo" para un «tú" y como un "tú» para un "yo». La relación no es entendida como un acercamiento psicológico, interno al yo, ni como un fenómeno cosmológico u holista, propio de un mundo que contiene en sí a los individuos: es una estructura ontológica originaria, es una realidad no comprendida en el yo ni comprendente al yo, sino efectivamente existente entre el yo y el tú. La relación no está fundada en la subjetividad, sino en la esfera de la relación entre los seres.

En obras más tardías (cfr. Elementi dell'interumano, 1954), Buber regresa a la teoría de la relación aclarando que, en su opinión, es necesario no confundir el componente social con el interhumano de la relación: el mundo humano es social en cuanto ligamen recíproco que genera experiencia y reacciones comunes (social es "el ser miembro de un grupo»), y es humano en cuanto las personas pueden liberarse de sus pertenencias colectivas (de tipo durkheimiano) y de sus funciones de rol (de tipo parsoniano), para entrar y vivir la relación intersubjetiva yo-tú, donde rige la reciprocidad de la mirada y del diálogo, donde se es compañero en los acontecimientos de la vida, donde se es percibido como "totalidad existente» ${ }^{15}$. En este sentido, Buber se aproxima a aquellos que, después de Husserl, han tratado la relación social como relación de empatía en sentido fuerte (Edith Stein), es decir, como capacidad para ubicarse en la posición del otro y así entenderlo más plenamente (concepto distinto de la simpatía). Ahora bien, conviene precisar que Buber insiste en considerar un error todo intento de comprender los fenómenos interhumanos como fenómenos psíquicos. El motivo es el siguiente: el significado de la relación no se encuentra en uno de los dos interlocutores o en ambos conjuntamente, sino sólo en su ser «inter» ${ }^{16}$.

Aunque procedente de otros orígenes culturales (Escuela de Frankfurt),

15 «La esfera de lo inter-humano es aquella del reciproco estar-el uno-frente-a otro; es el desplegarse de aquello que llamamos dialógico" (M. Buber, 1954: 87).

16 "El ámbito de lo inter-humano se extiende más allá de la simpatía (...), esto es lo decisivo: serno-objeto» (M. Buber, 1923: 297). 
también J. Habermas (1987) ha ubicado el sentido de la relación social en su carácter dialógico interpersonal (negando con ello el que se pueda hablar de relación social a nivel sistémico). En su opinión, una relación es socialmente (no sistémicamente) integrativa, y por ello humana, si y en la medida en que actúa una comunicación igualitaria y democrática, libre de constricciones, transparente y privada de motivaciones instrumentales (llamada "obrar comunicativo», por distinción con el "obrar estratégico»). La sociedad que él auspicia es identificada con una "comunidad ilimitada de discurso".

Recientemente, aunque sobre otras bases, algunos autores proponen considerar la relación social como una realidad multidimensional "dialógica», en la que interactúan una cultura, un sistema social y una personalidad, y que, como tal, es objeto fundamental de (en cuanto se constituye como) hermenéutica $^{17}$. En tal esquema, la relación adquiere grados de libertad (contingencia) sin girar en el vacío o ser reducida a pura comunicación. En este planteamiento es necesario leer la relación social como un texto que un sujeto escribe a otro sujeto (P. Ricoeur, 1986). Desde esta óptica, muchos estudiosos actualmente tratan a la relación social como "narración» que expresa y forja, de manera reticular e interactiva, las identidades sociales.

\section{LAS SEMÁNTICAS FUNDAMENTALES DE LA RELACIÓN SOCIAL: PROBLEMAS DE DEFINICIÓN}

Luis Gallino nos ha ofrecido la siguiente definición de relación social: "Modo de ser y de obrar de un sujeto por referencia genérica o específica a un otro determinado; contacto, ligamen, conexión entre dos o más sujetos, individuales o colectivos, de tal manera que siendo conocido un estado o comportamiento de uno de los sujetos es posible deducir aproximativamente el estado o el comportamiento correspondiente del otro» (1978: 558). Según Donati (1986: 243-244), esta definición no puede ser aceptada por diversos motivos. Fundamentalmente, porque es una miscelánea de los planteamientos anteriormente analizados sin un cuadro conceptual que unifique (aún más, tiende a identificar un "concreto» que sólo puede ser analizado en términos analíticos). La relación no solamente es una "referencia a», también —al mismo tiempo- es un "ligamen entre» (de otra manera, los aspectos simbólicos y de acción vienen escindidos de los estructurales y condicionales). La propiedad "genérico o específico" no es más que una de las posibles e infinitas modalidades. No se ha pedido estrictamente que el "otro» de la relación social esté determinado. La deducción del estado o comportamiento recíproco no es más que una modalidad particular de relación. Los tres aspectos que Gallino sucesivamente especifica son tan sólo inten-

17 Un buen ejemplo es J. Alexander (1982-83, 1988), que sigue parcialmente a Parsons, aunque lo critica. 
tos de diferenciar la relación del «contacto social» ${ }^{18}$, que, por otra parte, únicamente son otros casos particulares. Una vez más, la relación social es tratada como un "concreto" en clave psicosocial, más que en clave sociológica, y sin una articulada teoría analítica generalizada. Debe quedar claro que la relación, siendo desde el punto de vista filosófico una categoría primitiva del ser y del pensamiento, no puede ser explicada, aunque puede ser experimentada, observada y, dentro de ciertos límites, descrita. Ahora bien, como toda noción primera, no puede ser definida pero puede ser semantizada. Su importancia reside en el estar siempre presente como hecho constitutivo de la realidad y del conocimiento.

El pensamiento social premoderno tuvo dificultades para definir la relación social. El principal obstáculo fue el siguiente: asumir un punto de vista epistemológico en el que la noción de relación es un "concepto primero", autoevidente y no sometido a una posterior descomposición. Las Ciencias Sociales contemporáneas han abandonado este planteamiento y han iniciado una doble operación: por una parte, de problematización semántica y, por otra, de descomposición-rearticulación analítica de la relación social según diversas dimensiones y componentes. Tales operaciones introducen tres semánticas fundamentales que, en la actualidad, debemos considerar dentro de un único cuadro epistemológico ${ }^{19}$. Veámoslas brevemente:

a) La semántica referencial: entiende la relación como refero, o sea, como un referir cualquier cosa a otro dentro de un cuadro de significados simbólicos, con diferentes tipos y grados de intencionalidad, más o menos compartidos por los actores en campo. En esta línea se enmarcan las corrientes comprensivas y fenomenológicas (con sucesivos desarrollos en el interaccionismo simbólico, en la etnometodología, etc.).

${ }_{18}$ Recuerdo que, para el sociólogo italiano, la primera estaría caracterizada por el conocimiento que el sujeto tiene del nexo, de la referencia a personas y grupos, de la presencia o proximidad sensible o de imagen.

${ }^{19}$ La epistemología relacional afirma que no existe conocimiento sin relación, y decir relación equivale a entrar en un contexto que requiere la gestión de significados. Mientras que las filosofías objetivistas asumen como punto de partida lo designado, sobre el que recalcan el discurso, y las filosofías subjetivistas tienden a resolver el problema semántico mediante la función privilegiada y autoexpresiva del yo, la perspectiva relacional asume un discursco en el que la semántica, en cierto sentido, viene dada a priori, basta que la experiencia del discurso exista como relación, ya que no puede haber discurso donde no subsiste y no se expresa una forma de relación o de encuentro entre funciones subjetivas y objetivas de experiencia. De esta forma, la semántica aparece como una condición de la relacionalidad del discurso, el cual, en caso contrario, se reduciría a una expresión vacía sin contenido y significado (Actis Perinetti, 1959: 47). La perspectiva fenomenológica ilumina la debilidad de las posiciones positivistas ( $y$, en concreto, las neopositivistas del "Círculo de Viena»), que interpretan sintáctica y formalmente la relación. El programa positivista es una mera ilusión, en cuanto que los modos de articulación de la relación están conectados a su función semántica, que a su vez posee tantos aspectos como son los «universos de discurso» o posibles direcciones de experiencia. 
b) La semántica estructural: entiende la relación social como religo, o sea, como ligamen, conexión, vínculo, condicionamiento recíproco, estructura, que es al mismo tiempo vínculo y recurso, de carácter impersonal o suprapersonal. Aquí nos encontramos con las corrientes estructurales, corrientes que tienen su punto de partida en Marx y Durkheim.

A su vez, es posible descomponer estas dos dimensiones semánticas de la relación en posteriores componentes analíticos. También es posible buscar formas de integración entre estas semánticas y sus componentes internos. El intento más emblemático en tal dirección es aquel que interpreta la relación social según el esquema AGIL (Adaptation-Goal Attainment-IntegrationLatency) (P. Donati, 1991: cap. 4): el eje referencial (la relación como refero) viene interpretado en términos de referencias entre valores de base y determinados objetivos intencionales situacionales (eje L-G: latencia-realización de las metas, o bien cultura-personalidad) y el eje estructural (la relación como religo) en términos de medios conectados a normas de comportamiento (eje A-I: adaptación-integración, o bien sistema comportamental-sistema social).

La perspectiva que se obtiene es de gran importancia. Ante todo, se afirma que la relación social presupone cuatro componentes, o bien prerrequisitos funcionales, fundamentales: recursos, objetivos situacionales, normas y orientaciones de valor. En segundo lugar, se tiene un esquema para relacionar, sincrónica y diacrónicamente, los componentes de la relación social. La teoría neofuncionalista (N. Luhmann, 1984, 1993) reformula el esquema de la relación AGIL en los términos de un mecanismo autopoiético que actúa mecánicamente a través de una doble y simultánea distinción binaria: la distinción entre interno/externo del sistema social y la distinción antes/después de la dimensión temporal. En cualquier caso, la relación social viene considerada el fulcro del análisis social (P. Parlebas, 1992).

Otra formulación que combina las dos semánticas anteriores es la realizada por G. Bajoit (1992). Éste concibe la relación social como ligamen que presenta dos dimensiones fundamentales interconectadas entre sí: un ligamen de identidad (solidaridad) y un ligamen de diversidad (intercambio). Según este autor, las tradiciones teóricas pueden ser reconducidas a cuatro paradigmas (de la integración social, de la competición, de la alienación, del conflicto) que se caracterizan por el modo en que contemplan la relación social como mezcla de estos ligámenes en sus diversas articulaciones.

Sin embargo, las semánticas referenciales y estructurales de la relación describen una situación contemplada en un cierto tiempo y espacio. Están carentes de "generatividad»: o sea, dicen muy poco sobre qué genera las relaciones sociales y, sobre todo, cómo las relaciones sociales asumen un carácter generativo en cuanto "fenómenos emergentes", es decir, excediendo los elementos y las relaciones existentes precedentemente ${ }^{20}$.

${ }^{20}$ Desde un planteamiento morfogenético, emergente no sólo significa una rápida difusión y un rápido crecimiento. Sobre todo, significa que se libera de las interacciones, que crea algo imprevisto o que no se manifiesta a partir de los elementos iniciales (M. Archer, 1995). 
c) Por tanto, es necesario acceder a un tercer tipo de semántica que podríamos llamar "generativa». Ésta muestra cómo los diversos componentes y los variados sujetos agentes que entran en relación producen un efecto que no es explicable a partir de las propiedades de tales componentes y actores sociales, sino que asume connotaciones cuantitativas-cualitativas propias. Más allá de los planteamientos tradicionales que observan la relación en términos de energía afectiva (por ejemplo, M. Pages, 1970) y de ligamen simbólico y funcional (W. Stark, 1976-1983), algunos autores, reclamando más o menos explícitamente la idea simmeliana de efecto de intercambiabilidad o de reciprocidad (Wechselwirkung), han conducido estudios de carácter psicológico-social, especialmente en pequeños grupos, para investigar la relación social como "efecto de interacción». Su objetivo es resaltar tanto los efectos diversos de ego sobre alter como los de alter sobre ego. Éstos sólo pueden observarse y medirse si se toma como unidad de análisis no el individuo, sino la misma relación ${ }^{21}$.

En síntesis, cuando se afronta el problema de definir la relación social generalmente se tiende a utilizar una o más de las tres semánticas anteriores (referencial, estructural, generativa). Para una definición comprensiva de la relación social es necesario tenerlas presentes. De esta manera podemos decir que, desde el punto de vista de las Ciencias Sociales hodiernas, la relación social es aquella referencia — simbólica e intencional- que conecta los sujetos sociales en cuanto genera (también como simple actualización) un ligamen entre ellos, o sea, en cuanto expresa su "acción recíproca» (que consiste en la influencia que los términos de la relación tienen el uno sobre el otro y en el efecto de reciprocidad emergente entre ellos). «Estar (ser) en relación» puede tener un significado estático o dinámico, es decir, puede significar encontrarse en un contexto (morfostasis) o bien en interacción (morfogénesis). Por tanto, es oportuno distinguir entre relación social como contexto (o bien como matriz contextual, o sea, como situación de referentes simbólicos y conexiones estructurales observadas en un cierto campo «estático» de investigación) y relación social como interacción (o bien como efecto emergente en/desde una dinámica interactiva). En cualquier caso, el estar en relación comporta el hecho de que, obrando uno por referencia a otro, ego y alter no sólo se orientan y se condicionan recíprocamente, sino que dan lugar a una conexión sui generis que en parte depende de ego, en parte de alter y en parte es una realidad (efectiva o virtual) que no depende de los dos, sino que los «excede».

Poner de manifiesto este tertium, normalmente, refleja el punto de vista de un observador externo a los sujetos (ego y alter) en relación. También puede ser realizado desde ego y alter si y en la medida en que se colocan en un punto de

${ }^{21}$ Por ejemplo, W. Cook y A. Dreyer (1984) han elaborado con este motivo un «modelo relacional" para el estudio de la familia. A quien objeta que el planteamiento relacional termina perdiendo la identidad individual (el self), T. Tam (1989) ha respondido, aportando pruebas empíricas, que la interdependencia ego-alter no es una idea circular, sino que, al contrario, en la relación entendida como interacción el self se distingue y mantiene su autonomía. 
vista externo a sí mismos, pero esto es siempre muy problemático. De esta manera es posible comprender por qué, generalmente, los sujetos agentes no tienen conciencia de la relación social como cualquier cosa de «otro» respecto a las propias (singulares) motivaciones e intenciones subjetivas (dicho de otra manera: sólo sujetos altamente reflexivos, o bien sujetos que utilizan cibernéticas de segundo orden, pueden «objetivar» las propias relaciones).

Después de toda interacción, la relación que sirve de apoyo y que la actualiza ya no es la misma: se refuerza o se debilita; por tanto, cambia su cualidad. Y por ello las relaciones sociales no sólo admiten, sino que requieren necesariamente "historia», en cuanto que sólo pueden existir en el tiempo (J. M. Gottman, 1982). Se puede afirmar que las relaciones sociales tienen su código temporal que podemos llamar histórico-relacional (en el que el tiempo social tiene una duración, ya que la relación nace en un determinado momento, se desarrolla en un cierto lapsus de tiempo y posteriormente muere), diverso tanto del interactivo (en el que el tiempo social tiene la duración de un suceso) como del simbólico (en el que el tiempo social tiene las características de gran estabilidad, de "eternidad», o bien no tiene propiamente durée, en el sentido bergsoniano del término) (P. Donati, 1993: 46-47). Desde la perspectiva de la psicología social, la relación sirve de base a la (es el apoyo de la) interacción y la interacción expresa (actualiza o bien «rellena») la relación: si sólo nos quedamos en el nivel de la interacción se pierde la dimensión histórica de la vida social (J. Iglesias de Ussel, 1987).

El tipo y grado de relacionalidad también definen una categoría de bienes sociales llamados "bienes relacionales». Su característica fundamental es no ser ni estrictamente públicos ni estrictamente privados, de no ser competitivos según juegos de suma cero y de solamente poder ser producidos y consumidos conjuntamente por los participantes, en las redes informales (bienes relacionales primarios) y en las redes asociativas (bienes relacionales secundarios); concretamente, en aquellas esferas sociales autoorganizadas que no dependen estrechamente del Estado (que actúa a través del poder político y la ley) ni del mercado (que actúa mediante el dinero y el correspondiente sistema de precios) (P. Donati, 1993b: cap. 2).

Según recientes aportaciones del pensamiento sociojurídico (H. Willke, 1985), la relacionalidad social también caracteriza a un tipo de estructura legal, mejor dicho normativa. Ésta, a diferencia de los ordenamientos jurídicos o normativos de tipo condicional (que actúan a partir de órdenes o normas del tipo "si sucede $X$, entonces se debe hacer $Y_{»)}$ ) y finalista (que actúan por objetivos y proyectos), actúa a través de reglas que vienen producidas por continuos relacionamientos de los sujetos relevantes. El paradigma puede aplicarse al campo de las políticas sociales como sistema de observación-diagnóstico-guía relacional (ODG):

- (Observación) Generalmente, un programa de bienestar parte de la observación de un estado de necesidad sin ser capaz de conceptualizar y advertir la propia autorreferencialidad. Dicho en otros términos, se inicia con la 
definición de las necesidades sociales, pero éstas se observan desde un sistema que es externo a lo observado y, en la mayor parte de las ocasiones, se debe reconocer que no se poseen instrumentos de conocimiento de las «necesidades efectivas» de las personas en las que se debe actuar.

En sociología, recientemente se ha puesto de manifiesto que la observación tiene un carácter paradójico en cuanto expresa (describe) el sistema que observa y no la realidad observada. Se dice que el referente primario de la observación es el sistema que observa. La observación es una autorreferencia.

Desde el punto de vista práctico, en las relaciones entre operador social y usuario de los servicios de asistencia, los actores interactúan en el terreno de la no-transparencia mutura. Toda mente es opaca por/a sí misma.

Ahora bien, esta teoría, que pretende afrontar las dificultades de comprensión de las necesidades sociales, es excesivamente reductiva. Nace en el ámbito de las ciencias biofísicas y, al ser trasplantada al ámbito de lo social, olvida los rasgos distintivos de las relaciones en este campo de la realidad. Ciertamente, la mente no es transparente, pero, por este motivo, existe la cultura como conjunto de referentes simbólicos que nos aproximan a las representaciones necesarias para comprendernos en la comunicación. Por otra parte, aunque es correcto considerar un procedimiento cognitivo que se inicia con la problematización de la realidad, sin embargo, es erróneo cuando se eleva el método a conocimiento. Desde el punto de vista epistemológico, asumir este punto de vista teórico significa ubicar la «sospecha» como primera presuposición general de la teoría, difícilmente conciliable con las exigencias del realismo crítico que son propias del análisis y de la práctica de los sistemas ODG.

La teoría autorreferencial nos ha liberado de las premisas del realismo ingenuo y del voluntarismo ideológico. Nos ha enseñado que se puede ver aquello que no se ve cuando somos conscientes de que no se ve. Sólo si ego y alter son conscientes de su intrasistémica y mutua no-transparencia, la interacción puede pasar de ser una "caja negra" a una interacción "clara», capaz de captar reflexivamente los sistemas en interacción.

Por tanto, la observación de las necesidades sociales no es imposible o improbable; más bien habría que decir que no puede prescindir de la preliminar interacción entre el sistema que interviene y el sujeto destinatario.

- (Diagnóstico) Una intervención concreta presupone una descripción valorativa de la condición en la que se quiere intervenir. Dicha descripción se realiza en términos de distinciones entre patología y normalidad (de forma más general, entre estado satisfecho e insatisfecho), es decir, un diagnóstico. Éste es un caso especial de descripción que condensa la observación general de una situación a través de la focalización de la diferencia entre situación o comportamiento normal (o satisfecho) y patológico (o insatisfecho).

Ahora bien, describir algo significa observarlo (distinguirlo) y trasladar dicha observación a una forma semántica. Ya hemos hablado anteriormente de la observación y de sus premisas. Por lo que respecta al trasplante semántico, 
decir que se trata de construcciones sociales que se apoyan en la comunicación mediante el lenguaje, pero éste no es simplemente una serie de signos y de mensajes. También es una elaboración de sentido (como significado e intencionalidad), y el sentido es una relación a la relación. Éste es el límite de los sistemas expertos y de las inteligencias artificiales. Aunque puedan ofrecer un apoyo cognitivo, al elaborar un "diagnóstico» no pueden sustituir este relacionamiento, que solamente es humano.

Las teorías cognitivas han revelado que para que una descripción sea adecuada es necesario:

a) Que la reducción realizada por el observador a través de su sistema de referencia sea tematizada mediante el uso de otros puntos de vista (hecho que puede realizarse ubicándose en otros puntos de vista).

b) Que el operador sea consciente de los límites de sus descripciones para conceptualizar el problema social.

c) Que se recurra a una revisión del diagnóstico, por lo menos en los casos de mayor incerteza; la revisión debe entenderse como el juicio de una tercera parte (individual o de grupo) sobre el diagnóstico diferencial entre sistema que observa y sistema observado.

El sistema interactivo entre operador social y sistema-objeto de la intervención (como entre formulación de un programa y su implementación) se convierte en una "caja transparente» cuando se pasa de un juego de prueba-y-errores a una interacción lingüística e instructiva.

Operativamente son necesarias "muchas descripciones de trabajo»: tales descripciones sirven como modelos de simulación que serán válidos mientras describan bien el comportamiento de alter o el desarrollo de una situación. Obviamente, esto implica aceptar y tratar las negaciones y controversias que pueden emerger de tales comportamientos o evoluciones.

Por todo ello, un diagnóstico no arbitrario, en condiciones de complejidad, implica una cierta suma de controversias. Lo que confirma que los sujetos destinatarios de la intervención no pueden ser diagnosticados desde un sistema experto externo que pretenda pasar por encima de sus cabezas.

En conclusión, el diagnóstico es algo más que una observación-descripción-comunicación lingüística: es una relación social, y como tal debe ser pensada y activada.

Es inevitable aceptar cierta negociación entre diagnósticos diferenciales. El arte de la intervención se apoya en transformar el disentir y el carácter emotivo contingente de las descripciones en un proceso capaz de aprendizaje no sólo cognitivo, sino también afectivo y simbólico-moral.

- (La intervención como guía relacional) Ni las intervenciones directivas (programas autoritarios, condicionales, «racionales») ni las paradójicas (rituales, de connotación positiva de los síntomas o de liberalización del comporta- 
miento desviado) han sido apropiadas para los sistemas sociales complejos hodiernos, los cuales tienen como rasgo central comportarse contraintuitivamente.

Más adecuados pueden ser los programas relacionales. Éstos son capaces de combinar procesos de aprendizaje conjuntamente cognitivos y normativos con una configuración del sistema interactivo que permita autorregularse a los actores que individúan fines comunes que cada uno persigue autónomamente en el propio ámbito de acción. Se trata de un proceso de diferenciación e integración reflexiva por parte de subsistemas sociales autogestionados que actúan en networks de elevada complejidad.

La «guía relacional» no es una forma de concertación ${ }^{22}$. La concertación no es el modelo apropiado de "guía relacional». Quien piensa en la concertación como filosofía de planificación tiene en la cabeza un modelo estructuralista y mecanicista de los sistemas ODG, el cual pretende orientar a los actores mediante el control del contexto (se habla de una intervención indirecta porque sostiene que es posible condicionar la condiciones contextuales).

La idea-eje de la guía relacional es que son los mismos sujetos participantes en los programas de bienestar los que elaboran la definición de lo que debe ser hecho, por quién, cómo y cuándo, en términos de máxima reciprocidad posible. Sólo ellos pueden observar y diagnosticar la situación. Sólo ellos pueden interiorizar y activar las decisiones acordadas. La guía es llamada relacional en cuanto que las intervenciones deben respetar la integridad de actores autónomos y, al mismo tiempo, promover un cambio estructural organizado (P. Donati, 1991: cap. 5).

Evidentemente, nos encontramos ante una relacionalidad que actualmente se aleja del concepto de relación como simple ligamen social, o sea, como fuerza implícita de una norma social precedente y dominadora de los individuos (como aún la conceptualizan la mayor parte de los autores).

\section{RELACIONES Y REDES SOCIALES}

Desde los años cincuenta y sesenta, especialmente en los países anglosajones, a partir de la antropología estructural-funcionalista, se ha desarrollado el llamado "análisis de redes sociales» (network analysis) ${ }^{23}$. Aunque raramente se admite, estos estudios deben mucho a la sociometría de J. L. Moreno (1953, 1956), estudioso teórico experimental de las relaciones interpersonales y de los pequeños grupos (fundador de la revista Sociometry. A Journal of Interpersonal Relations, aparecida en 1937).

22 En esta línea se enmarcan las aportaciones de H. Willke (1985).

${ }^{23}$ R. M. McIver, A. R. Radcliffe-Brown, J. A. Barnes, S. Nadel, E. Bott, J. C. Mitchell: un interesante resumen, en F. Piselli (1995). 
Con el concepto de red no sólo se intenta poner de manifiesto que los individuos existen en un contexto de relaciones, es decir, que tienen ligámenes referenciales y estructurales entre sí, sino - y es diverso- que "existe una relación entre estos ligámenes» ${ }^{24}$, o sea, que lo que sucede entre dos nudos de la red influencia las relaciones entre los otros nudos, bien sean las más próximas (que tienen relaciones directas), bien sean las más distantes (que tienen relaciones indirectas). La red no es un conjunto de individuos entre sí, sino que es el conjunto de sus relaciones.

Desde sus inicios, la network analysis ha tenido un carácter prevalentemente metodológico, como aplicación de las Ciencias Estadísticas, de la teoría de los grafos y del cálculo matricial a un modelo de sociedad concebido como conjunto de puntos y líneas (el instrumental formalizado y matematizado continúa progresando: S. Wasserman y K. Faust, 1994). Muy fecundos han sido los resultados empíricos (N. Nohria y R. G. Eccles, 1992).

Actualmente, no es propio hablar de una "teoría» de las redes sociales basada en network studies; no hemos de olvidar que son estudios conducidos en términos ateóricos. Deben mucho tanto a las teorías de carácter sistémico (estructuralistas y positivistas, que tratan la red como un todo, siendo llamada whole network) como a las teorías de tipo accionista (individualistas y, a menudo, utilitaristas, que tratan la red como un conjunto de individuos en contacto con un individuo ubicado en el centro; por ello es llamada ego network). De esta forma, es muy raro que la relación social aparezca como unidad focal de análi$\operatorname{sis}^{25}$. También existen investigaciones a gran escala mediante muestras representativas de la población nacional. En Francia, por ejemplo, F. Héran (1988a, $19886)$ y M. Forsé $(1991,1993)$ han estudiado empíricamente las redes de socialidad, distinguiéndolas en redes de sociabilidad (entendidas como conjuntos de relaciones concretas entre individuos y/o grupos primarios) y redes de societabilidad (que contemplan las relaciones más abstractas entre individuos y grupos secundarios). Para ello se amparan en un planteamiento que une al análisis de redes una sensibilidad por el concepto de "grupalidad" (entendido como «fenómeno social total») (J. Baechler, 1996).

$\mathrm{El}$ análisis de redes conduce al llamado "paradigma de redes». Éste trata la sociedad no como el paradigma parteltodo (basado en la analogía orgánica y en el que podemos inscribir el pensamiento de Tönnies), tampoco como el paradigma sistemalambiente (desarrollado por Parsons y el primer Luhmann), ni como el paradigma de la autopoiesis (elaborado por el Luhmann más reciente amparándose en las ciencias biológicas y cognitivas; en concreto, las aportaciones de H. Maturana y F. Varela), sino como "red de redes de relaciones».

Es muy importante comprender la relación entre el concepto de red y el de

${ }^{24}$ La expresión es de R. Firth, citado por M. Forsé (1991: 259).

${ }^{25}$ Incluso los más recientes intentos en tal dirección - R. S. Burt (1982) y B. Wellman y S. D. Berkowitz (1988) - derivan en una forma holista de "análisis estructural» en el que es la estructura o red social total la que determina las características de los actores, sus comportamientos y sus singulares relaciones diádicas, sin que se pueda contemplar la otra cara de la moneda. 
sistema. El primero es mucho más amplio que el segundo, no viceversa. Los sistemas son una especie de "condensación» de las redes, en el sentido de que las redes conducen (son conductoras de) más realidad de cuanto podemos contemplar en términos de redes comunicativas, con nudos, densidad, funcionalidad, conexión y otras características «sistémicas». Dicho en otros términos, el concepto sociológico de red incluye al de sistema sin poder ser reducido a sistema: visto desde una óptica de redes, el sistema social es (i) una dimensión analítica de la red que (ii) pone de manifiesto las interdependencias funcionales y (iii) "estabiliza» — mediante nudos de unión/desunión_los mecanismos retroactivos y los circuitos a través de los que se expresa la fenomenología social. Pero también la red es el conductor, el lugar, la forma en que otros aspectos y dimensiones de lo social toman vida y se expresan. La sociedad aparece como un mix de formal e informal que requiere un nuevo paradigma de observación.

Este paradigma no sólo representa una forma descriptiva de los fenómenos sociales y no sólo elabora un específico aparato metodológico. Implica, lo desea al menos, una epistemología relacional. La premisa más general del pensar sociológico podría ser la siguiente: al principio es (está) la relación. Tal premisa debe ser entendida en sentido realista y no relativista ${ }^{26}$. El proceso social, con todas sus características, procede por, con y a través de relaciones. Más concretamente, desde una epistemología relacional, el conocimiento sociológico (fig. 1):

a) Se inicia con la definición del propio objeto como relación social entre sujetos (A y B) que están ubicados en diversas estructuras socioculturales.

b) Se observan los fenómenos desde el punto de vista relacional, es decir, colocándose en la situación de un observador tercero $(\mathrm{O})$ que contempla el comportamiento de una actor (A) hacia otro (B) y viceversa (el comportamiento de $\mathrm{B}$ hacia $\mathrm{A}$ ), así como la relación que emerge de tal interacción (efecto $\mathrm{Y}$ ). Éste es el objeto o problema cognoscitivo desde el que se ha partido, convirtiéndose de esta forma en objeto de una específica teoría.

Esto se puede decir tanto de la realidad social (fenomenológica) como de la teoría (observación y reflexión de la realidad social). Relacional es tanto el hacerse de la realidad social como del pensamiento, que va desde las dimensiones teóricas a los hechos empíricos y viceversa, en un continuo proceso de reflexividad entre diversos pasajes y fases, también metodológicas, intermedias, siempre relativamene autónomas.

Trasladar la relación al nivel de premisa general primera, en el ambiente metafísico del conocimiento, no implica de ninguna manera asumir la absoluta

${ }^{26}$ Como dice J. Pieper, desde el punto de vista filosófico: «Pertenece a la naturaleza de lo real ser un posible objeto de conocimiento humano. De ninguna manera existe una separación total entre la realidad objetiva y el intelecto humano; cuando dirigimos nuestra mirada al mundo de las cosas existe ya, primera y precedentemente, una relación» (1981: 160). 


\section{FIGURA 1}

La observación relacional es aquella hecha desde $O$ (observador tercero, diferente de los agentes $A$ y $B$ ) que observa las relaciones entre $A$ y $B$ y su efecto emergente $(Y)$

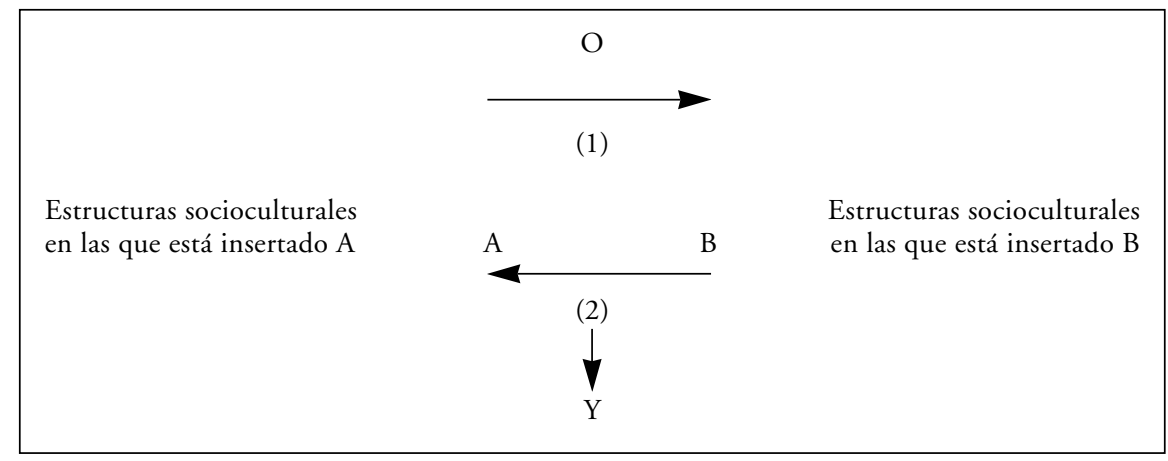

contingencia del mundo social. Tampoco implica acogerse a cualquier ontología que niegue el sujeto. Al contrario, significa asumir que la relación tiene su «raiz» (o, si se prefiere, una referencia) no contingente, mientras se despliega en la contingencia. Obviamente, tal raíz o referencia, más acá y más allá de la sociedad dada, supera la concreta fenomenología social. De esta forma se desata una ambivalencia que ha recorrido la cultura occidental hasta nuestros días. La ambivalencia persona/comunidad o, si se prefire, individuo/sociedad. En la cultura clásica el individuo se encuentra en una situación ambigua: por una parte, se dice que está en la comunidad como la parte al todo; por otra, no pertenece completamente a la comunidad ${ }^{27}$. Con el desarrollo de la relacionalidad en el mundo moderno, esta ambivalencia es estructural: la persona humana crece al mismo tiempo en la dependencia y en la autonomía respecto a la comunidad/sociedad de pertenencia. El singular individuo siempre es parte de ella, pero al mismo tiempo la trasciende. Para comprender esta realidad es necesario abandonar la metáfora parte/todo. Al mismo tiempo, es evidente que debe ser abandonado el positivismo. Este último siempre ha querido hacer del individuo un producto de la sociedad (precisamente la parte del todo).

Desde el punto de vista sociológico sólo la relación en sí misma es necesaria, mientras que en su desplegarse refleja la efectiva contingencia del mundo social, que es «así», pero también podría ser diverso. Lo podría, pero no lo es: si es así, lo es porque la relación, necesaria en sí misma, hace también necesaria la exigencia de las determinaciones (las particularidades históricas) que, sin embargo, en sí mismas, más allá de nuestro sistema de referencia, son contingentes.

${ }^{27}$ Como dice Tomás de Aquino: por un lado, «qualibet persona singularis comparatur ad totam communitatem sicut pars ad totum» (S. Th. II-II, 64, 2); por otro, "homo non ordinatur ad communitatem politicam secundum se totum et secundum omnia sua» (S. Th. I-II, 4 y 3 ). 
Dicho brevemente, siempre es necesario ver en qué sentido, modo y grado viene utilizada (o no) una teoría de las relaciones sociales en sentido específico. En las últimas décadas, en el análisis de redes, hemos asistido a una creciente diferenciación entre los aspectos estructurales (objetivos, impersonales) y los aspectos culturales (subjetivos, intencionales). Hay incluso quien advierte la necesidad de una integración entre tales dimensiones (P. Di Maggio, 1992). En mi opinión, son diferenciaciones e, incluso, separaciones que, aun estando presentes en ciertos fenómenos empíricos, deben ser reconsideradas a la luz de un concepto más "completo", aunque al mismo tiempo más diferenciado y articulado, de relacionalidad. Aplicado al análisis de la relación social, personalmente creo que el término "completo» comparte algo con el sentido contenido en la thick description de la que habla Geertz (1973: cap. 1) ${ }^{28}$, pero: a) no estoy de acuerdo con Geertz cuando afirma que "las formas de la sociedad son la sustancia de la cultura», y b) sostengo que el sentido del que se habla debe ser observado de manera específica desde el punto de vista sociológico. Los círculos en intersección de Simmel han sido una primera formulación, pero en la actualidad el "fenómeno red» ha desarrollado paradigmas de análisis más sofisticados, hecho éste paralelo a la diferenciación de la relación social en la sociedad. En esta dirección caminan algunos estudiosos de los movimientos sociales que han puesto de manifiesto cómo tales movimientos se generan y regeneran a partir de la activación de «identidades reticulares» (A. Melucci, 1984).

El paradigma de redes conduce a una específica pragmática relacional, entendida como forma de intervención (de servicio social, de terapia, de política social) en la/sobre la sociedad. La idea base es que la operatividad de una sociología que sirva de apoyo a acciones prácticas debe tener claro que:

a) No existen sujetos y objetos aislados, sino complejas tramas relacionales en las que sujetos y objetos se definen relacionalmente, auto y poiéticamente. Esto no significa de manera relativista, como si todo fuese modificable a placer o según el caso; el problema de la relatividad se resuelve especificando las relaciones entre los diversos sistemas de referencia. En el caso del análisis sistémico significa precisar las «variables de situación» del sistema no trivial de referencia.

b) Cuando se interviene en un sujeto u objeto se debe actuar en la trama relacional en que se contempla que está insertado, es decir, considerando otros sujetos y objetos del entorno y los «efectos de red» que las acciones pueden implicar.

c) Siempre se debe ser consciente de que existe una relacionalidad entre quien observa y quien es observado, entre quien actúa y sobre quien se actúa. Dicha relacionalidad posee una connotación de círculo hermenéutico, pero no indeterminado ad infinitum.

${ }^{28}$ Es decir: la pluralidad de los planos de discurso, la multidimensionalidad de los significados y su no agotamiento. 
Obviamente, existen niveles variables en los que todo esto puede ser considerado, conocido (en concreto, medido) y puesto en práctica. Pero lo importante es no legitimar reducciones selectivas a priori.

En la actualidad asumen particular importancia los modelos de «intervención (o trabajo) de redes» (C. Loriedo, 1978; L. Sanicola, 1993; F. Folgheraiter, 1994) entendidos como sistemas de acciones que:

1) A partir de un «mapa de redes» (en que se estudian las características relacionales como la densidad, la conexión, la multiplexity, etc.) se proponen modificar la realidad actuando sobre relaciones, o sea, produciendo cambios de los contextos y de los comportamientos a través de la modificación de las relaciones existentes.

2) Tratan de activar las "potencialidades naturales» de las redes sociales.

3) Utilizan formas mixtas de relacionamientos (es decir, interseccionando relaciones formales e informales, primarias y secundarias, cooperativas y conflictivas, etc.).

En la medida en que la relación social se presenta como el objeto de los nuevos servicios sociales, también aparece como el fulcro de un análisis profesional y ético del trabajo social (R. Constable, 1992).

\section{LA RECOMPOSICIÓN DE LO HUMANO Y DE LO SOCIAL: EL PLANTEAMIENTO RELACIONAL}

Si tuviésemos que sintetizar en una fórmula los principales problemas de la sociedad contemporánea, podríamos decir que nos encontramos ante «un progresivo distanciamiento entre lo humano y lo social» (P. Donati, 1994: 158). Esto está presente tanto en el nivel de las concretas relaciones sociales como en el nivel de la interpretación sociológica. Lo social ya no es concebido como el lugar donde habite lo humano. Este último es contemplado como carácter, impulso, molestia, «rumor» externo respecto al sistema de comportamientos, mecanismos y reglas que "hacen» la sociedad. Generalmente solemos decir: el mercado tiene sus reglas, la política tiene sus juegos, los mass media tienen su lógica, etc. El sujeto humano fluctúa en el ambiente del sistema social. Lo humano se identifica con las necesidades, los deseos, los sueños de un «sujeto» que es percibido y representado como externo e indeterminado respecto a las relaciones sociales organizadas (identificadas con el sistema social).

$\mathrm{Si}$ contemplamos los principales planteamientos sociológicos, desde el marxista al funcionalista, desde el fenomenológico al hermenéutico, su principal límite consiste en la incapacidad para plantear de una manera adecuada el problema de lo «humano» en lo social. Por este motivo, mientras asistimos al progresivo avance del planteamiento "hipermodernista» luhmanniano, que, como se ha visto, relega lo "humano» al «ambiente» del sistema social, la socio- 
logía se divide entre autores modernos y postmodernos. Tanto unos como otros plantean propuestas interesantes, pero sin producir respuestas satisfactorias. El planteamiento "relacional» o, mejor aún, "personalista-relacional» debería cubrir este vacío. Veamos brevemente cómo se articula.

A diferencia de los que piensan que todo lo social es sistema (Luhmann), de los que, al contrario, sostienen que sólo lo humano expresa lo social (los individualistas), o que lo social se debe distinguir entre lo «sistémico» y lo humano del "mundo de la vida» (Habermas), el planteamiento relacional presenta una perspectiva en la que lo humano y lo social son diferentes pero, al mismo tiempo utilizo un término luhmanniano-, están constantemente «interpenetrados»: ninguno de los dos términos se agotan mutuamente, sino que ambos están destinados, aunque variablemente, a estar el uno dentro del otro. "La sociedad está hecha de relaciones en las que jamás puede ser anulada la distinción humano/no humano, diferenciándose la una de la otra mediante procesos contingentes; la sociedad está allí, en cuanto que los mecanismos funcionales requieren y demandan relaciones, y no sólo comportamientos en los que las orientaciones subjetivas de los actores son irrelevantes o factores a eliminar; hablar de "sociedad de lo humano" significa considerar que la sociedad humana no es ya un dato in-meditato, sino que debe ser producida reflexivamente mediante atribuciones de sentido a los nexos en los que lo humano se diferencia de lo no humano» (P. Donati, 1994: 170).

Se trata de un planteamiento que, sin ningún tipo de prejuicios respecto a la modernidad, sin embargo, no tiene la preocupación de presentarse como «moderno». Tampoco esconde detrás de sí intenciones de tipo ideológico. Quizás por este motivo consigue ofrecer una representación, parcial como todas las representaciones pero "adecuada» a nuestra realidad social, en la que se expresa tanto el sentido profundo de sus patologías, así como una vía plausible para su superación. "Podemos decir que una forma social es humana en cuanto que sus relaciones sociales están producidas por sujetos que se orientan reciprocamente a partir de un sentido suprafuncional» (P. Donati, 1994: 171): éste es el eje central del planteamiento relacional. Su íntima intención polémica con el funcionalismo es evidente; sin embargo, su fuerza reside en la capacidad de utilizar de forma diversa la arquitectura conceptual. "El análisis social no puede distinguirse de cuestiones relativas a quien actúa; y quien actúa está dentro y fuera del sistema social, es decir, el sistema social puede considerarse como el ambiente del sujeto humano, y viceversa; el limite entre humano y social existe en virtud de esta relación inmanencialtrascendencia de lo humano respecto a lo social $y$, viceversa, de lo social respecto a lo humano» (P. Donati, 1994: 173).

Obviamente, siempre es necesario saber hasta qué punto puede ser inmediatamente trasplantada a la realidad social cualquier "antropología filosófica» o que lo humano pueda ser definido por la sociología, quizás, como "pura construcción social»; igualmente, es necesario saber que toda teoría sociológica, cualquiera que sea su objeto o su función, depende de la forma en que es articulada su relación con lo «humano». En este sentido, creo que el planteamiento relacional aporta algunos elementos decisivos. 
En primer lugar, permite redefinir lo social más allá del «dilema clásico», siempre vivo y activo, que lo considera una proyección individual o algo independiente del sujeto (por un lado, Weber; por otro, Durkheim). En segundo lugar, posibilita una teoría "crítica» de la "modernización» centrada en algunos de sus límites humanos, pero no haciendo concesiones a las «utopias» de la Escuela de Frankfurt ni a cierto revanchismo tradicionalista que, con buenas dosis de cinismo, parece gozar de la crisis en la que nos encontramos. Los límites de la modernización "no pueden concebirse como barreras más o menos estables, como si fueran recintos que deberian contener las acciones sociales dentro de un humano preestablecido. Pueden desplazarse, y de hecho se desplazan, relacionalmente. Dicho en otros términos: los umbrales de la diferenciación no se encuentran predefinidos, sino sujetos a posteriores relacionamientos» (P. Donati, 1994: 173).

Como se puede constatar, la estrategia relacional no implica un rechazo de la contingencia o de la complejidad de nuestro mundo. Más bien trata de afrontarla teniendo presente la radical indeterminación entre los límites humanos y no humanos que parecen estar presentes en las sociedades avanzadas. Por ello busca y trata de defender una instancia normativa centrada en la "calidad humana» de determinadas relaciones sociales. "Toda forma social expresa una determinada calidad de las relaciones. Dicha calidad es la que decide el tipo y grado de humanidad que contiene esa forma social respecto a otras» (P. Donati, 1994: 172).

No debemos olvidar que nos encontramos ante una teoría que, al pretender ser «sociológica», puede abandonar el problema filósofico referente a la antropología que asumimos como criterio de juicio del «tipo» y del "grado» de "bumanidad» de una determinada relación social. Por ello, resulta muy significativo que el planteamiento relacional se distancie de las antropologías débiles, relativistas, de la muerte del hombre y, sin embargo, camine hacia su superación para salvar lo «bumano» que hay en lo social.

\section{BIBLIOGRAFÍA}

Actis Perinetti, L. (1959): Dialettica della relazione: saggio di filosofia relazionale, Edizioni di Comunità, Milán.

Alexander, J. (1982): Theoretical logic in sociology, vol. I: Positivism: presuppositions and current controversies, University of California Press, Berkeley.

- (1983): The modern reconstruction of classical thought: Talcott Parsons, University of California Press, Berkeley.

- (1988): "The centraly of the classics», en A. Giddens y J. H. Turner (comps.), Social theory today, Polity Press, Cambridge.

- (1990): Teoria sociologica e mutamento sociale. Un'analisi multidimensionale della modernità, Angeli, Milán.

AQuino, Tomás de (1961): Summa Theologiae, BAC, Madrid. 
Archer, M. (1995): Realist Social Theory: The Morphogenetic Approach, Cambridge University Press, Cambridge.

- (1997): La morfonegesi della società, Angeli, Milán.

Ardigo, A. (1980): Crisi di governabilità e mondi vitali, Cappelli, Bolonia.

BAEChler, J. (1996): "Gruppi e sociabilità», en R. Boudon (comp.), Trattato di sociologia, Il Mulino, Bolonia, pp. 63-113.

BAjOIT, G. (1992): Pour una sociologie relationelle, PUF, París.

BAteson, G. (1976): Verso un'ecologia della mente, Adeplhi, Milán.

- (1984): Mente e natura, Adeplhi, Milán.

BAUDrillard, J. (1968): Il sistema degli oggettí, Bompiani, Milán.

- (1984): Le strategie fatali, Feltrinelli, Milán.

Bearman, P. (1993): Relations into Rhetorics. Local Elite Social Structure in Norfolk, England, 1540-1640, New Brunswick, N. J.

Benton, T. (1993): Natural Relations. Ecology, Animal Rights and Social Justice, Verso, LondresNueva York.

Boudon, R. (1981): Effetti perversi dell'azione sociale, Feltrinelli, Milán.

- (1982): La lógica de lo social, Rialp, Madrid.

Bourdieu, P. (1992): Risposte. Per un'antropologia riflessiva, Bollati Boringhieri, Turín.

Blau, P. (1960): «Structural Effects», en American Sociological Review, vol. 25, núm. 2.

Buber, M. (1993): Io e tu (1923), Distanza originaria e relazione (1950), Elementi dell'interumano (1954), en Il principio dialogico e altri saggi, Cinisello Balsamo, Roma.

BurT, R. S. (1982): Toward a Structural Theory of Action. Network Models of Social Structure, Perception, and Action, Sage, Beverly Hills.

Castón Boyer, P. (1996): «La sociología de Pierre Bourdieu», en REIS, núm. 76, pp. 75-97.

Coleman, J. (1990): Foundations of Social Theory, Harvard University Press, Cambridge (Mass.).

CONSTABlE, R. (1992): «Relazionalità e appartenenza: fondamenti per una riflessione etica sul lavoro sociale», en F. Villa (comp.), Dimensioni del servizio sociale, Franco-Angeli, Milán.

CoOK, W., y DreYer, A. (1984): «The Social Relations Models», en Journal of Marriage and the Family, 46, 3, pp. 679-687.

COPI, I., y BEARD, R. W. (1966): Essays on Wittgenstein's Tractatus, Londres.

Di Maggio, P. (1992): «Nadel's Paradox Revisited: Relational and Cultural Aspects of Organizational Structure», en N. Nohria y R. G. Eccles (comps.), Networks and Organizations: Structure, Form, and Action, Boston (Mass.), pp. 118-142.

Di Nicola, P. (1986): L'uomo no é un’insola. Le reti sociali primarie nella vita quotidiana, Angeli, Milán.

- (1998): Le reti come metafora dell'appartenenza. Analisi structturale e paradigma di rete, Angeli, Milán.

Donati, P. (1986): Introduzione alla sociologia relazionale, Franco-Angeli, Milán.

- (1991): Teoria relazionale della società, Franco-Angeli, Milán.

- (1993a): «Pensamiento sociológico y cambio social: hacia una teoría relacional», en REIS, núm. 63, pp. 29-51.

- (1993b): La cittadinanza societaria, Laterza, Roma-Bari.

- (1994): «Sulla distinzione umano/non umano. Per una sociologia del duemila», en El Mundo 3, núm. 2, pp. 158-177.

- (1998): Lezioni di Sociologia, CEDAM, Padua.

Durkheim, E. (1964): Las reglas elementales del método sociológico, Dédalo, Buenos Aires.

- (1967): De la división del trabajo social, Schapire, Buenos Aires.

- (1928): El suicidio, Reus, Madrid.

- (1968): Las formas elementales de la vida religiosa, Schapire, Buenos Aires.

- (1971): Le Socialisme, PUF, París.

- (1976): Pragmatismo y Sociología, Shapire, Buenos Aires.

EkeH, P. P. (1974): Social Exchange Theory: The Two Traditions, Harvard University Press, Cambridge (Mass.). 
Emirbayer, M. (1997): "Manifiesto for relational sociology», en American Journal of Sociology, 103, 2, pp. 281-317.

Folgheraiter, F. (1994): Operatori sociali e lavoro di rete, Erickson, Trento.

FORSÉ, M. (1991): «Les rèseaux de sociabilité: un état des lieux, en L'Année Sociologique, 41, pp. $245-264$.

- (1993): «La fréquence des relations de sociabilité: typologie et évolution», en L'Année Sociologique, 43, pp. 189-212.

FreUnd J. (1990): «Relation et activité sociales», en Etudes sur Max Weber, Ginebra-París, cap. III.

Gadamer, H. G. (1980): Verdad y Método, Sígueme, Salamanca.

Gallino, L. (1978): Dizionario di sociologia, Utet, Turín.

GARFINKEL, H. (1967): Studies in Ethomethodology, Englowood Cliffs, N. J.

GeErTZ, C. (1973): The Interpretation of Cultures, Basic Books, Nueva York.

Goffman E. (1967): Interaction Ritual, Garden City, Nueva York.

- (1969): Strategic Interaction, Filadelfia.

- (1974): Frame Analysis, Hamper and Row, Nueva York.

GotTman, J. M. (1982): «Temporal Form: Toward a New Language for Describing Relationships», en Journal of Marrige and the Family, 44, 4, pp. 943-962.

GrAmSCI, A. (1951): "Gli intellettuali e l'organizzazione della cultura», en Quaderni dal Carcere, Einaudi, Turín.

Gurvitch, G. (1950): La vocation actuelle de la sociologie, París.

Habermas, J. (1987): Teoría de la acción comunicativa, Taurus, Madrid.

HADDEN, R. W. (1988): "Social Relations and the Content of Early Modern Science», en The British Journal of Sociology, 39, 2, pp. 255-280.

HÉRAN, F. (1988a): "Au coeur du réseaux associatif: les multi-adhérents", en Economie et Stadistique, 208, Mars, pp. 33-44.

- (1988b): «La sociabilité, une pratique culturelle», en Economie et Stadistique, 216, Decembre, pp. 3-22.

Horstmann, R. P. (1984): Ontologie und Relationen. Hegel, Bradley, Russel und die Kontroverse über interne und externe Beziehungen, Hain Königstein.

Husserl, E. (1962): Ideas, FCE, México.

IgLeSIAS DE UsSEL, J. (1987): «El tiempo en la sociedad contemporánea», en Política y Sociedad. Estudios en Homenaje a Francisco Murillo Ferrol, vol. I, CIS/Centro de Estudios Constitucionales, Madrid, pp. 113-133.

KeEneY, B. P. (1983): Aesthetics of Change, Nueva York-Londres.

Krempel A. (1952): La doctrine de la relation chez Saint Thomas. Exposé historique et systématique, Vrin, París.

LÉVI-STRAUSS, C. (1967): Le structture elementari della parentela, Feltrinelli, Milán.

LORIEDO, C. (1978): Terapia relazionale, Astrolabio, Roma.

Luhmann, N. (1984): Soziale Systeme, Frankfurt.

- (1993): «Perché AGIL?», en Teoria Sociologica, I, 1, pp. 157-175.

MarX, K. (1968a): «Prólogo», en F. Hegel, Filosofía del Derecho, Claridad, Buenos Aires.

- (1968b): La ideología alemana, Pueblos Unidos, Montevideo.

- (1969): Manuscritos: economía y filosofía, Alianza, Madrid.

- (1971): El capital, vols. I, II y III, FCE, México.

Mauss, M. (1950): Sociologie et Antropologie, PUF, París.

MCLuhan, M. (1964): Understanding media, Signet, Nueva York.

MeAd, G. H. (1934): Mind, Self and Society from the Standpoint of a Social Behaviorist, Chicago.

- (1977): On Social Psychology. Selected Papers, Chicago University Press, Chicago.

MeluCCI, A. (1984): Altri codici. Aree di movimento nella metropoli, Il Mulino, Bolonia.

Miralbell, I. (1994): El dinamismo voluntarista de Duns Escoto. Una transformación del aristotelismo, Eunsa, Pamplona.

Moreno, J. L. (1953): Who Shmall Survive?, Beacon House, Nueva York.

- (1956): Sociometry and the Science of Man, Beacon House, Nueva York. 
MünCH, R. (1989): «Structures, Cultures and Knowledge: A Historical Comparative Exploration», en H. Haferkamp (ed.), Social Structure and Culture, De Gruyter, Berlín, Nueva York, pp. 37-66.

Muzzetto, L. (1997): Fenomenologia, etnometodologia. Percorsi della teoria dell'azione, Angeli, Milán.

Nohria, N., y Eccles, R. G. (comps.) (1992): Networks and Organizations: Structure, Form, and Action, Boston (Mass.).

PACI, E. (1954): Tempo e relazione, Taylor, Turín.

- (1965-66): Relazioni e significati, 3 vols., Ed. Lampugnani Nigri, Milán.

PAGÉs, M. (1970): La vie affective des groupes. Esquisse d'une théorie de la relation humaine, París.

PARlebas, P. (1992): Sociométrie, réseaux et communication, PUF, París.

PARSONS, T. (1937): The Structure of Social Action, Nueva York.

- (1961): «Somes Considerations on the Theory of Social Change», en Rural Sociology, vol. 26, núm. 3, pp. 219-239.

- (1966): Societies. Evolutionary and Comparative Perspectives, Englewood Cliffs, Prentice-Hall (N.J.).

- (1978): Action Theory and the Human Condition, Nueva York.

Piaget, J. (1964): Etudes sociologiques, Droz, Genève.

Pieper, J. (1981): «La verità delle cose», en Studi Cattolici, núm. 250.

PISELlI, F. (comp.) (1995): Reti. L'analisi di network nelle scienze sociali, Roma.

Plenge, J. (1930): Zur Ontologie der Beziehug. Kleine Schriften, Universidad de Munich, Munich.

Ricoeur, P. (1986): Du texte à l'action. Essais d'hermeneutique II, Editions du Seuil, París.

SANICOLA, L. (1993): L’intervento di rete, Nápoles.

Savage, S. P. (1981): The Theories of Talcott Parsons. The Social Relations of Action, MacMillan, Londres.

SCHÜTZ, A. (1962): Collected Papers, L'Aia.

- (1974a): La fenomenologia del mondo sociale, Il Mulino, Bolonia.

- (1974b): Estudios sobre teoría social, Amorrortu, Buenos Aires.

- (1977): Il problema della rilevanza, Rosenberg and Sellier, Turín.

SHuO, Y. (1993): «Mise en scène des relations lors d'un banquet chinois», en Archives Européennes de Sociologie, tomo 34, 1, pp. 17-40.

Simmel, G. (1926-27): Sociología, 2 vols., Revista de Occidente, Madrid.

Somers, M. R. (1994): "The Narrative Constitution of Identity: A Relational and Network Approach", en Theory and Society, 23, 5, pp. 605-649.

STARK, W. (1976-1983): The Social Bond. An Investigation into Bases of Law-abidingness, 4 vols., Nueva York.

TAM, T. (1989): «Demarcating the Boundaries Between Self and the Social: The Anatomy of Centrality in Social Networks", en Social Networks, 11, 4, pp. 387-401.

TARDE, G. (1895): Les lois de l'imitation, París.

TÖnnies, F. (1947): Comunidad y Sociedad, Losada, Buenos Aires.

Toulemont, R. (1962): L'essence de la société selon Husserl, París.

Varela, F. (1984): «Two Principles for Self-Organization», en H. Ulrich y G. J. Probst (comps.), Self-Orgnization and Management of Social Systems, Springer Verlag, Berlín.

VIERKANDT, A. (1915): «Die Beziehung als Grundkategorie des soziologischem Denkens», en Archiv für Rechts und Wirtschafstsphilosophie, IX, 1-2.

Wasserman, S., y Faust, K. (1994): Social Network Analysis: Methods and Applications, Cambridge.

Weber, M. (1964): Economía y Sociedad, 2 vols., Fondo de Cultura Económica, México.

- (1969): La ética protestante y el espíritu del capitalismo, Península, Barcelona.

Wellman, B., y Berkowitz, S. D. (comps.) (1988): Social Structures. A Network Approach, Cambridge.

WIESE, L. (von) (1955): System der allgemeinen Soziologie, Duncker \& Humblot, Berlín. 
Willke, H. (1985): «Three Types of Legal Structure: The Conditional, the Purposive and the Relational Progam», en G. Teubner (comp.), Dilemmas of Law in the Welfare State, De Gruyter, Berlín, pp. 280-298.

WINCH, P. (1958): The Idea of a Social Science, Londres.

\section{ABSTRACT}

These pages aim to offer the key for reading society as a relationship. An attempt is made to clarify the way in which the social relationship is an object of sociological knowledge, how it can be observed, and the way in which society is a continuous process of association and dissociation, in other words, of differentiation that is not always linear and continuous but also non-linear (asymmetrical) and reactionary (not evolutionist in the Darwinian sense, as traditionally thought). 